\title{
Credit default swaps and market information
}

$\operatorname{AUTHOR}(\mathrm{S}):$

Osano, Hiroshi

\section{CITATION:}

Osano, Hiroshi. Credit default swaps and market information. Journal of Financial Markets 2020, 48: 100498.

\section{ISSUE DATE:}

2020-03

URL:

http://hdl.handle.net/2433/250447

\section{RIGHT:}

(c) 2019. This manuscript version is made available under the CC-BY-NC-ND 4.0 license

http://creativecommons.org/licenses/by-nc-nd/4.0/; The full-text file will be made open to the public on 01 March 2022 in accordance with publisher's 'Terms and Conditions for Self-Archiving'.; This is not the published version. Please cite only the published version.; この論文は出版社版でありません。引用の際には出版社版をご確認ご利用ください。 


\title{
Credit default swaps
}

\author{
and \\ market information*
}

Hiroshi Osano ${ }^{\dagger}$

May 11, 2019

${ }^{*}$ I am grateful to the coeditor (Gideon Saar) and an anonymous referee for their helpful and valuable suggestions. I would also like to thank seminar participants at the Contract Theory Workshop for their useful comments.

${ }^{\dagger}$ Institute of Economic Research, Kyoto University, Sakyo-ku, Kyoto 606-8501, Japan. Tel: +81-75-7537131. email: osano@kier.kyoto-u.ac.jp 


\title{
Credit Default Swaps and Market Information
}

\begin{abstract}
In this paper, I theoretically explore the effects of the interaction between the information transmission role and the empty creditor problem of credit default swaps (CDSs) under debt rollover. Contrary to the empty creditor argument, the introduction of CDS protection increases the possibility of out-of-court restructuring if the liquidation value is not sufficiently large. However, when it is large, the introduction of CDS protection increases the possibility of firm bankruptcy. In addition, the introduction of CDS markets impairs the efficiency of debt financing under certain conditions, particularly if the liquidation value is not sufficiently large.
\end{abstract}

JEL Classification: D86, G14, G33.

Keywords: credit default swaps, debt contract, empty creditor, liquidity, transparency. 


\section{Introduction}

The empty creditor problem arises when lenders protected by credit default swaps (CDSs) oppose the out-of-court restructuring of distressed firms and help push these firms into bankruptcy or liquidation. ${ }^{1}$ The reason is that empty creditors (that is, those insured with CDSs) have little incentive to agree to an out-of-court restructuring that would avoid bankruptcy, because formal default triggers immediate payment from protection sellers for the lenders' exposure. This implies that CDS protection makes lenders tougher negotiators in any outof-court restructuring, and in extreme cases it may act against renegotiation altogether. Nonetheless, the CDS market is a better place to assess a firm's credit risk. ${ }^{2}$

More specifically, if CDS market participants can acquire information about the firm's future prospects, that information is revealed by CDS prices and this influences the beliefs of debt market participants, thus strongly affecting the rollover decision of lenders. In fact, CDS prices are also affected by the initial debt contract chosen by lenders because the net profits of CDS market participants depend on it. However, the initial debt contract is determined by predicting the rollover decisions of lenders. Furthermore, the empty creditor problem under debt rollover essentially relates to the rollover decisions of lenders. Thus, the

\footnotetext{
${ }^{1}$ I define firms as all reference entities whose default risks are insured by CDSs. In the context of sovereign debt, bankruptcy (out-of-court restructuring) needs to be interpreted as involuntary (voluntary) debt restructuring because no international bankruptcy court applies to sovereign issuers.

${ }^{2}$ For corporate bonds, several empirical studies find that information mostly flows from CDS prices to bond prices, and that in practice, the CDS market for a firm can be more liquid than that for the firm's bonds (see Hull et al., 2004; Blanco et al., 2005; Norden and Wagner, 2008; Stultz, 2010; and Das et al., 2014; although Hull et al. include CDS quotes on sovereigns or quasi-sovereigns). However, regarding the relative informational efficiency of CDSs and stock markets, the literature provides mixed results. Acharya and Johnson (2007) suggest that there is incremental information revelation in CDS prices relative to equities. Using a much larger sample than Acharya and Johnson (2007) and modifying their definition of credit protection dummies, Qiu and $\mathrm{Yu}$ (2012) confirm this argument by finding that there is a greater information flow from the CDS market to the stock market ahead of major credit events. Conversely, Hilscher et al. (2015) dispute the argument of Acharya and Johnson (2007) by suggesting that equity returns lead to credit protection returns. Using stock market- implied credit spreads, Forte and Peña (2009) also find that stocks lead CDS and bonds. However, Jorion and Zhang (2007) show that CDS spreads are more sensitive to downside risk than equity prices. Elsewhere, Hotchkiss and Ronen (2002), Ronen and Zhou (2013), and Kedia and Zhou (2014) suggest that bond markets are at least as informationally efficient as related equities. As argued in Jorion and Zhang (2007), some credit events, such as an increase in leverage, imply differing movements across the CDS and equity markets such that stock prices may not be good measures of credit risk. Indeed, using more comprehensive data, Lee et al. (2018) show that CDS spreads contain unique information not captured by other securities, such as the stocks and bonds of the same firm.
} 
effect of CDSs on the rollover decisions of lenders is not straightforward. Indeed, empirical studies of this problem report mixed results (see Subsection 6.2).

In this article, I explore the interaction between the role of information transmission and the empty creditor problem of CDSs under debt rollover, and provide new empirical implications and novel insights into the regulation of CDSs following the 2008-09 financial crisis. I characterize CDSs both as a vehicle that causes empty creditors and as a market that creates information. Hence, CDSs make initial lenders tougher negotiators while the CDS prices convey information acquired by speculators and influence the decisions of (potentially empty) creditors at debt rollover. These two roles of CDSs create a type of feedback effect.

Based on the framework of Bolton and Oehmke (2011), I formalize a model in which a lender makes a debt contract with a firm that has a project, but no funds. Both the lender and the firm have only opaque information about the firm's future cash flows. In the CDS market modeled à la Kyle (1985), a speculator acquires information by spending money to profit from CDS trading, ${ }^{3}$ while a market maker clears the market by collecting trade orders from the speculator, as well as noise traders and lenders. Furthermore, speculative trading is concentrated in the CDS market.

Exploiting the feedback effect discussed above, the lender determines how much information about the firm's future cash flows will be revealed in the CDS market. More specifically, the lender can change the net profits of CDS trades by designing a debt contract, thereby influencing the information acquisition decision of the speculator. This influences the quality of information received by the speculator, and thus, alters the trading strategy of the speculator. As CDS prices then change, the quality of information from CDS prices is also affected. As a result, the lender can indirectly influence the informativeness of CDS prices. Indeed, the lender faces a trade-off between the more ex post efficient rollover decision and the greater renegotiation surplus from the stronger bargaining position owing to CDS protection. Nonetheless, while improving the quality of information from CDS prices enables

\footnotetext{
${ }^{3}$ If a CDS involves corporate bonds, the lender may be a speculator because of insider trading, as argued in Acharya and Johnson (2007) and Qiu and Yu (2012). I discuss this case in Subsection 6.1, and show that the main results are unaffected by this modification.
} 
lenders to select the more ex post efficient rollover decision, it may also reduce the ex ante expected payoff of empty lenders whose bargaining position in renegotiation increases as a result of CDS protection. Then, improving the quality of information from the CDS prices may harm lenders because there is a discrepancy between the social and lenders' benefits from transparency in CDS prices. This implies that the optimal initial debt contract may prevent CDS prices from producing more transparent information about the firm's future prospects and may thereby increase the likelihood of out-of-court restructuring.

The main results of the paper are as follows. For the first main result, suppose that early liquidation of the project is inefficient if there is no additional information, but is efficient if the firm's future prospects are revealed to be bad. Then, contrary to the empty creditor argument, if the liquidation value is not sufficiently large, the introduction of CDS protection increases the likelihood of out-of-court restructuring at debt rollover and impairs the efficiency of equilibrium and debt financing. However, if the liquidation value is sufficiently large, the introduction of CDS protection increases the likelihood of firm bankruptcy at debt rollover and is more likely to impair (improve) the efficiency of equilibrium and debt financing if the CDS market is more (less) liquid and/or the initial belief in profitability uncertainty is more (less) optimistic. This result differs from that in Bolton and Oehmke (2011): if early liquidation of the project is inefficient and the liquidation value is not sufficiently large, the introduction of the CDS market leads to either efficient out-of-court restructuring or inefficient firm bankruptcy, even in the parameter setting of this analysis in which both strategic default and no financing are omitted. The difference stems from my setting in that only the speculator can directly learn the firm's future cash flows.

Intuitively, disclosing more transparent information may reveal that the firm's future prospects are bad and induce the lender to liquidate the firm with low cash flows at debt rollover. However, this reduces the ex ante expected payoff of the lender if the liquidation value is not sufficiently large and if the increased level of credit protection improves her bargaining position and raises her ex ante expected payoff in renegotiation. Thus, if early liquidation of the project is inefficient when there is no additional information, the lender 
can commit to increasing the likelihood of out-of-court restructuring at debt rollover by designing a debt contract that merely results in the poor informativeness of the CDS price. In contrast, if the liquidation value is sufficiently large, the lender can commit to increasing the likelihood of firm bankruptcy by designing a debt contract that enhances the informativeness of the CDS price. With regard to the efficiency, the introduction of CDSs can create benefits from the information on their prices because the initial lender can effectively liquidate the firm with low cash flows. However, the introduction of CDSs may involve not only renegotiation costs incurred by the initial lender and the firm in any out-of-court restructuring, but also costs incurred by the speculator. In light of the above argument, the introduction of CDS markets impairs the efficiency of equilibrium and debt financing if the liquidation value is not sufficiently large, or if the liquidation value is sufficiently large but the costs of CDS introduction outweigh the benefits.

My result implies that the introduction of CDS protection prevents firm bankruptcy and promotes inefficient renegotiation in out-of-court restructuring from a social perspective by generating less transparent information in the CDS market, but only if the liquidation value is not sufficiently large. This novel result regarding the effect of CDS introduction on the efficiency of debt financing is obtained given the interaction between the informativeness of market trading in CDS markets and the empty creditor problem with debt rollover.

Practically, my result also suggests that the introduction of CDSs increases the likelihood of the out-of-court-restructuring (or bankruptcy) of the firm and impairs (or may or may not impair) the efficiency of debt financing if the fraction of non-fixed assets and/or R\&D expenditures is higher (or lower). ${ }^{4}$ Then, despite the empty creditor problem, the results predict that the introduction of CDSs increases the probability of out-of-court restructuring and raises the inefficiency of debt financing in firms in at least some industries, such as information technology and bioscience, because in these industries the share of non-fixed assets and/or R\&D expenditures in firms is typically high. On the other hand, my findings suggest that with the subprime mortgage-backed securities (MBS) referenced by CDS contracts, the

\footnotetext{
${ }^{4}$ Davydenko and Strebulaev (2007) and Lee, Oh, and Yermack (2017) suggest that the share of non-fixed assets and/or R\&D expenditures is a good proxy for liquidation costs.
} 
introduction of CDSs increases the probability of bankruptcy and impairs the efficiency of debt financing if the initial belief is sufficiently optimistic, because of the higher share of fixed assets.

The second important contribution of this paper is that if the informativeness of the signal received by the speculator is determined exogenously, out-of-court restructuring is more likely to arise when the signal received by the speculator is more informative. Conversely, if the informativeness of the signal received by the speculator is endogenously determined, out-ofcourt restructuring is more likely to occur when the CDS market is more liquid.

When the informativeness of the signal received by the speculator is determined exogenously, the more informative signal increases the potential ex ante expected gains from avoiding bankruptcy for the lender relative to the losses from renegotiation costs if it is probable that the firm's future cash flows are low. Similarly, when the informativeness of the signal received by the speculator is determined endogenously, the more liquid CDS market increases transparency and enhances the informativeness of the signal received by the speculator, thereby increasing the potential ex ante expected gains from avoiding bankruptcy for the lender relative to the losses from renegotiation costs if it is probable that the firm's future cash flows are low.

These results show that the more informative signals received by speculators in CDS markets and more liquid CDS markets increase the likelihood of inefficient out-of-court restructuring. The results yield new insights when there is a link between the informativeness of market trading in CDS markets and the empty creditor problem under debt rollover. My model also provides a tractable framework to assess policy interventions. I evaluate the policies of increasing liquidity in CDS markets and banning CDS markets in Subsection 6.3.

The remainder of the paper is organized as follows. I review the literature in Section 2. In Section 3, I present the model setting. In Section 4, I derive the optimal debt contract in the absence of CDS markets. I investigate the optimal debt and CDS contracts in the presence of CDS markets in Section 5. In Section 6, I discuss some extensions, and provide the empirical and policy implications of the model. Concluding remarks are in Section 7. 
All proofs are in the Appendix.

\section{Related literature}

This paper relates to several recent studies on the effect of CDSs on lender strategy. Bolton and Oehmke (2011) emphasize the effect of CDSs on renegotiation between debtors and creditors, and analyze the empty creditor problem. They argue that by strengthening creditor bargaining power, CDSs raise the debtor's pledgeable income, increase the set of projects that can receive financing, and serve to reduce the incidence of strategic default. However, they also suggest that CDSs cause an inefficiently high incidence of costly bankruptcies by inducing creditors to overinsure in equilibrium. Unlike their analysis, I incorporate the information transmission role of CDS markets, and clarify the interaction between the informativeness of market trading in these markets and the empty creditor problem under debt rollover by focusing on the situation in which there is no strategic default and the firm can always finance its project by signing an initial debt contract appropriately. ${ }^{5}$

Piccolo and Shapiro (2017) analyze the interaction between credit ratings and CDS markets as a type of feedback effect by considering the following trade-off: more accurate ratings decrease the informativeness of market trading in CDS markets because they diminish the incentives of speculators to acquire information in CDS markets, whereas the more informative trading increases the incentives for the credit rating agency to be accurate because it increases transparency about whether the credit rating agency inflated ratings. In contrast, I incorporate the empty creditor problem and consider the interaction between the informativeness of market trading in CDS markets and the empty creditor problem under debt rollover as a type of feedback effect. I can therefore discuss whether the introduction of CDSs results in the greater likelihood of out-of-court restructuring by generating opaqueness in price discoveries in CDS markets, even though the empty creditor problem prevails.

\footnotetext{
${ }^{5}$ Focusing on the difference between the trading costs of CDSs and bonds, Oehmke and Zawadowski (2015) provide a model in which the introduction of CDSs crowds out the demand for the bond, but improves bond allocation by allowing long-term investors to hold a long position in the bond, purchase CDS protection, and absorb more of the bond supply. Danis and Gamba (2018) extend the model in Bolton and Oehmke (2011) to a dynamic framework of investment and financing and calibrate the dynamic model.
} 


\section{The model}

I consider a firm that generates cash flows at dates 1 and 2 by undertaking a two-period investment project. The firm has no initial wealth, finances the project by issuing debt to lenders, and is protected via limited liability. However, there is also a market for CDSs that reference the debt. All of the agents are assumed to be risk neutral.

\subsection{Cash flows, liquidation, and out-of-court restructuring.-}

The firm's project requires an initial investment $F$ at date 0 , and generates cash flows $C_{1}$ at date 1 and uncertain cash flows $C_{2}$ at date 2. $C_{2}$ can be interpreted as the continuation value of the firm. Following the realization of $C_{1}$, the project can be liquidated for a verifiable liquidation value $L(>0)$ at date 1 , while the liquidation value is reduced to zero at date 2 . I assume that $C_{1}$ is verifiable at date 1 and can be contracted upon at date 0 , whereas none of the date 2 cash flows can be contracted upon at date 0, following Bolton and Oehmke $(2011,2012) .{ }^{6}$ In practice, for various reasons, the firm cannot finance all of the required funds using long-term debt. However, I also assume that the firm can observe $C_{2}$ at date 2, and that lenders can make $C_{2}$ verifiable at date 2 only when they seize control of the firm at date 2 if the firm cannot make the contractual repayment at date 2. In particular, I assume that the firm's date 2 cash flows are equal to $C_{2}^{b}\left(C_{2}^{g}\right)$ with probability $\theta(1-\theta)$ at the bad (good) state, and that $C_{2}^{b}<C_{2}^{o}<C_{2}^{g}$, where $C_{2}^{o} \equiv E_{0} C_{2}=\theta C_{2}^{b}+(1-\theta) C_{2}^{g}$.

I also assume that the initial lender offers a debt contract to the firm at the beginning of date 0 . Hence, I assume that the initial lender has full bargaining power at the beginning of date 0 . The debt contract at date 0 specifies a contractual repayment $R$ at date 1 . I assume that $C_{1}<F$. Under limited liability of the firm, this assumption implies that the project cannot be financed with debt that is repaid only from the cash flows at date 1 ; instead, the firm needs to roll over the initial debt by borrowing from the initial lender or new lenders at date 1. I assume that the rolled over debt market is competitive because the firm's project

\footnotetext{
${ }^{6}$ As in Bolton and Oehmke (2011), the justification for this assumption is that it is too opaque and complicated for debt contracting parties to stipulate the future cash flows accurately in an enforceable contract at date 0 . In fact, my main results are unaffected even if the firm can finance part of the required funds using long-term debt.
} 
profitability at date 2 is not too opaque or complicated at date 1 . Thus, the face value of the rolled over debt is exactly equal to the expected payoff from the rolled over debt. However, even if part of the firm's surplus is received by the holders of the rolled over debt, the main results are unchanged.

If the firm can roll over the debt, it has the right to continue the project at date 2 , and can collect a part of $C_{1}+C_{2}$ at date 2 if a contractual repayment $R^{\prime}$ of the rolled over debt is fully compensated for by $C_{1}+C_{2}$; otherwise, the holders of the rolled over debt receive a residual claim on the firm.

If the firm fails to roll over the debt, the initial lender has the right to discontinue the project and liquidate the firm. The liquidation can be interpreted as either outright liquidation in the form of Chapter 7-type cash auctions or Chapter 11-type reorganization. In the latter case, $L$ expresses the expected payment the initial lender can receive from Chapter 11 reorganization. Note that because $C_{1}$ is verifiable at date 1 , the firm does not default strategically: the firm cannot choose to stop servicing its debt obligations as long as it is able to repay the face value of debt $R$.

Instead of liquidation in the case of debt default, the firm and the initial lender can choose an out-of-court restructuring through a debt exchange. ${ }^{7}$ The out-of-court restructuring involves renegotiation costs, which reduce the renegotiation surplus available to the firm and the initial lender from $C_{1}+C_{2}$ to $\lambda\left(C_{1}+C_{2}\right)$, where $\lambda \in(0,1)$. However, I assume that $C_{1}$ $+L<\lambda\left(C_{1}+C_{2}^{o}\right)$. This implies that the out-of-court restructuring is ex ante expected to be less costly than liquidation at date 0 if there is no additional information. In the out-of-court restructuring, the renegotiation surplus is divided between the firm and the initial lender at date 2, according to their relative bargaining strengths. I assume that in the absence of CDSs, the relative bargaining strengths in renegotiation for the firm and the initial lender at date 2 are exogenously given by $q$ and $1-q$, respectively. ${ }^{8}$

\footnotetext{
${ }^{7}$ The out-of-court restructuring examined in this paper does not include a prepackaged bankruptcy (prepack) because I assume that none of the date 2 cash flows can be contracted upon at date 0.

${ }^{8}$ Once the firm has spent the borrowing fund on the project, the liquidation value of the project may depend on the firm's specific knowledge of the project. Thus, the firm and the initial lender have the bargaining power $q$ and $1-q$ at date 2 because the bargaining power changes at date 2 .
} 


\subsection{The CDS market.-}

The initial lender can purchase CDSs to insure against nonpayment of the contract. Practically, in a CDS contract, a protection buyer pays a premium to a protection seller, in exchange for a payment from the latter if a credit event occurs. In this model, the CDS contract is specified as follows. Let $p^{c d s}$ denote an equilibrium price per unit of trade of the CDS and $x$ the net total trade of the CDS. Then, after the debt contract is signed, the CDS contract at date 0 is such that the buyer pays the amount $p^{c d s}$ per unit of trade to the seller, whereas the seller agrees to pay the buyer an amount 1 per unit of trade in a credit event at date 1 or date 2 and zero otherwise. I assume that according to standard practice in CDS markets, a credit event occurs at date 1 if the firm fails to roll over the debt and if the firm and the initial lender fail to renegotiate the debt contract with mutually acceptable terms in an out-of-court restructuring. ${ }^{9}$ I also assume that a credit event occurs at date 2 if the firm cannot repay the face value of the rolled over debt.

If the initial lender purchases the CDS, the relative bargaining position at date 2 can change because the CDS protection increases the initial lender's outside options. More specifically, the firm must compensate the initial lender up to the sum of the liquidation value and the level of credit protection in order to be able to renegotiate. Thus, if the sum of the date 1 cash flows, the liquidation value, and the level of credit protection exceeds the available renegotiation surplus $\lambda\left(C_{1}+C_{2}\right)$, renegotiation becomes impossible.

I model the CDS market as a competitive insurance market involving risk-neutral buyers and sellers: trading occurs between the initial lender, a speculator, noise traders, and a competitive market maker, and $p^{c d s}$ is priced fairly using a simplified model à la Kyle (1985). ${ }^{10}$

The speculator decides whether or not to acquire information about the firm's date 2 cash flows. If the speculator attempts to acquire the information, the speculator receives a private signal $\omega \in\{b, g, o\}$ at date 0 . If $\omega=b(\omega=g)$, the speculator receives precise information

\footnotetext{
${ }^{9}$ For a justification of why out-of-court restructuring does not constitute a credit event for CDS contracts, see Bolton and Oehmke (2011, p. 2627).

${ }^{10}$ Until Subsection 6.1, I assume that the initial lender cannot be a speculator. However, if the initial lender has access to nonpublic information on the firm through her lending and investment banking activities, the initial lender can be a speculator. In Subsection 6.1, I discuss this case and show that the main results are unaffected by such an extension of the model.
} 
that the firm's date 2 cash flows are $C_{2}^{b}\left(C_{2}^{g}\right)$. On the other hand, if $\omega=o$, the speculator cannot obtain any new information. Thus, the speculator forecasts that the firm's date 2 expected cash flows are $C_{2}^{o}$. However, the speculator can privately choose the probability of observing an informative signal $\omega=b$ or $g$ at a cost $c(\alpha)$, where $\alpha$ is the probability of the speculator obtaining $\omega=b$ or $g$; and $c^{\prime}(\alpha)>0, c^{\prime \prime}(\alpha)>0, c(0)=c^{\prime}(0)=0$, and $c(1)$ $=\infty$. Let $x^{s}$ denote the speculator's demand for the CDS: $x^{s}<0$ if the speculator sells the CDS protection, and $x^{s}>0$ if the speculator buys the CDS protection. I assume that the speculator in the CDS market does not participate in the debt market. This assumption is consistent with Oehmke and Zawadowski (2015), who suggest that speculative trading concentrates in CDS markets because of its relative liquidity advantage. ${ }^{11}$

Some part of the total flow of trade orders for the CDS comes from noise traders. Let $x^{n}$ denote the noise traders' demand for the CDS. For simplicity, I assume that $x^{n}=n(>0)$ with probability $\frac{1}{2}$, and $x^{n}=-n$ with probability $\frac{1}{2}$.

The market maker observes the total trade order flow $x=x^{s}+x^{n}+x^{\ell}$, where $x^{\ell}$ denotes the initial lender's demand for the CDS. However, the market maker does not know the identity of any of the traders submitting orders. After observing $x$, the market maker sets a price $p^{c d s}$, which equals the expected CDS payment conditional on $x$. As a result, the expected profit of the market maker is zero. I assume that the market maker rationally anticipates the information acquisition and CDS trading strategies of the speculator, as well as the rollover and CDS trading strategies of the initial lender.

In equilibrium, the face value of debt in the debt contract at date $0, R$, the reorganization cost in the out-of-court restructuring, $1-\lambda$, and the speculator's cost function, $c(\alpha)$, are common knowledge. I further assume that the CDS price $p^{c d s}$ and the credit event are observed by all the agents, including new lenders entering at date 1. Hence, having observed $p^{c d s}$, the participants in the debt market update their beliefs about the firm's date 2 cash flows. In addition, I assume that at date 0 all the agents know that the firm's date 2 cash

\footnotetext{
${ }^{11}$ A number of empirical studies report high trading costs in corporate bond markets, which are contrasted with the significantly lower trading costs in CDS markets. See Bessembinder et al. (2006), Edwards et al. (2007), and Bao et al. (2011).
} 
flows are equal to $C_{2}^{b}\left(C_{2}^{g}\right)$ with probability $\theta(1-\theta)$. However, note that only the speculator knows her received signal $\omega \in\{b, g, o\}$ and her choice of $\alpha$.

I assume that there would be no expected gains from trade in the CDS market except for the speculator, given that all of the parties are risk neutral. In this sense, CDS contracts are redundant securities. In the presence of CDSs, however, the relative bargaining position in renegotiation can change because the CDS protection increases the initial lender's outside option. Thus, in my model, save for the effect through the information transmission role, the only effect of introducing the CDS protection on the initial lender's ex ante expected payoff at date 0 is via making her the tougher negotiator in any out-of-court restructuring, as in Bolton and Oehmke (2011). ${ }^{12}$

\subsection{Timing of the model.-}

The timing of the model is described below and depicted in Figure 1.

(i) At the beginning of date 0 , the initial lender signs a debt contract with the firm. After the debt contract is signed, the speculator in the CDS market decides whether to acquire information about the firm's date 2 cash flows. If the speculator attempts to do so, the speculator privately chooses the probability of observing an informative signal $b$ or $g$ at a $\operatorname{cost} c(\alpha)$, and receives a private signal $\omega \in\{b, g, o\}$. Then, the speculator, noise traders, and the initial lender submit their orders $\left\{x^{s}, x^{n}, x^{\ell}\right\}$ so that $x=x^{s}+x^{n}+x^{\ell}$. Having observed $x$, the market maker sets a price $p^{c d s}$ to equal the expected CDS payment conditional on $x$, and the participants in the debt market update their beliefs about the firm's date 2 cash flows by observing $p^{c d s}$.

(ii) At date 1, $C_{1}$ are realized. If the firm can roll over the debt, the firm continues the project. If the firm fails to roll over the debt, the initial lender decides whether to liquidate the firm or renegotiate with it in an out-of-court restructuring. If the initial lender liquidates the firm, the buyer (seller) of the CDS receives (pays) the CDS payment.

(iii) At date 2, $C_{2}$ are realized. If the firm can repay the face value of the rolled over debt,

\footnotetext{
${ }^{12}$ Even if new lenders purchase the CDS at date 1 , the results of this analysis are unaffected because CDS contracts at date 1 are redundant securities and have no informational or bargaining role.
} 
it receives the residual part. If it cannot repay the face value of the rolled over debt, the holders of the rolled over debt receive the residual claim of the firm; and the buyer (seller) of the CDS receives (pays) the CDS payment.

The perfect Bayesian equilibrium serves as the solution concept. I specify an out-of-equilibrium belief to refine the equilibrium at the beginning of Subsection 5.2.

I implicitly assume (i) that the initial lender cannot commit to a specific level of protection after she signs a debt contract with the firm, and (ii) that the initial lender cannot trade her debt position in the secondary market after signing a debt contract. The first assumption is plausible because credit derivative positions do not have to be disclosed according to current market practice. As a result, the commitment to a certain level of protection is impossible for the initial lender after signing the debt contract. The second assumption reflects the empirical finding that trading costs are significantly higher for the corporate bond market than for the associated CDS market.

In the subsequent analysis, I assume that $C_{2}^{b}<L$. Thus, early liquidation is the ex post efficient decision when $\omega=b$. On the other hand, because I have already assumed that $C_{1}+L<\lambda\left(C_{1}+C_{2}^{o}\right)<C_{1}+C_{2}^{o}$, early liquidation is inefficient if there is no additional information, whereas rolling over the initial debt is the ex post efficient decision when $\omega$ $=o$ or $g$. I also assume that $F<\lambda\left(C_{1}+C_{2}^{o}\right)$. As shown in subsequent discussion, this assumption ensures that the firm can finance the initial investment by signing an initial debt contract, irrespective of the presence or absence of the CDS market.

\section{Optimal debt contracts without CDS}

I begin by analyzing the benchmark case in which there is no market for credit insurance.

If $R$ is sufficiently large, the firm may not roll over debt at date 1 because of insufficient earnings at dates 1 and 2. If the firm fails to roll over the debt at date 1 , the initial lender chooses to liquidate the firm or to renegotiate with the firm under an out-of-court restructuring. Considering the risk of debt rollover, the initial lender designs a debt contract so as to maximize her expected payoff at date 0 subject to the firm's individual rationality 
constraint at date 0 and the fair pricing constraint on the debt rolled over at date 1 . Hence, I obtain the following proposition.

Proposition 1. In the absence of CDS markets, the equilibrium face value of the debt is given by $R=C_{1}+C_{2}^{o}$. The firm can always roll over the debt and continue the project at date 1. The initial lender's expected payoff at date 0 is $C_{1}+C_{2}^{o}-F(>0)$; and the firm value at date 0 is equal to $C_{1}+C_{2}^{o}-F$.

Proposition 1 shows that in the absence of a CDS, $R$ is given by the maximal pledgeable cash flows of the firm at date $1, C_{1}+C_{2}^{o} \equiv C_{1}+\theta C_{2}^{b}+(1-\theta) C_{2}^{g}$. Note that without a CDS, none of the agents can receive any new information after the debt contract is signed. Thus, if the firm rolls over the debt at date 1, the firm's maximal pledgeable cash flows at date 1 are $C_{1}+C_{2}^{o}$.

Intuitively, if the firm can roll over the debt, the initial lender wants to maximize the face value of the debt, $R$, subject to the constraint of the firm's maximal pledgeable cash flows at date 1 . She then sets $R$ equal to $C_{1}+C_{2}^{o}$ in this case. Alternatively, if the initial lender sets $R$ to be sufficiently large and forces the firm to fail to roll over the debt at date 1 , her expected payoff is $(1-q) \lambda\left(C_{1}+C_{2}^{o}\right)-F$ in an out-of-court restructuring, and $\min \left(C_{1}+\right.$ $L, R)-F$ in liquidation. However, it follows from $C_{1}+L<\lambda\left(C_{1}+C_{2}^{o}\right)<C_{1}+C_{2}^{o}$ that the initial lender always prefers to roll over the debt by setting $R=C_{1}+C_{2}^{o}$ instead of forcing the firm to fail to roll over the debt at date 1.

The absence of CDS markets implies that no agents receive new information about the firm's date 2 cash flows at date 1 , thereby causing an inefficiency. Although it follows from $L$ $>C_{2}^{b}$ that liquidation would be more ex post efficient than continuation at date 1 if the bad state were forecast to definitely occur at date 2 , the firm rolls over the debt and continues the project at date 2 because of the lack of disclosure of this information.

\section{Optimal debt and CDS contracts in the presence of CDS markets}

\subsection{Debt rollover, liquidation, and out-of-court restructuring.-}

The game is solved through backward induction. I begin by examining how the initial 
lender's decision at debt rollover is determined by taking as given $R$ and her conjecture about the firm's date 2 cash flows. According to the size of $R$, I obtain the following lemma.

Lemma 1: (i) If $R \leq C_{1}+C_{2}^{b}$, the firm always rolls over the debt.

(ii) Suppose that $C_{1}+C_{2}^{b}<R \leq C_{1}+C_{2}^{o}$. If debt market participants infer that the speculator receives $\omega=b$, the firm fails to roll over the debt and the initial lender forces the firm into liquidation. If the debt market participants infer that the speculator receives $\omega=o$ or $g$, the firm rolls over the debt.

(iii) Suppose that $C_{1}+C_{2}^{o}<R$. The firm fails to roll over the debt and the initial lender renegotiates with the firm in an out-of-court restructuring if $C_{1}+L+x^{\ell} \leq \lambda\left(C_{1}+C_{2}^{o}\right)$ or forces the firm into liquidation if $C_{1}+L+x^{\ell}>\lambda\left(C_{1}+C_{2}^{o}\right)$.

Intuitively, if $R \leq C_{1}+C_{2}^{b}$, then $R$ is smaller than the least of the maximal pledgeable cash flows of the firm, regardless of the conjectures of the debt market participants regarding the firm's date 2 cash flows. Hence, the firm can always roll over the debt. If $C_{1}+C_{2}^{b}<$ $R \leq C_{1}+C_{2}^{o}$, then $R$ is larger (or smaller) than the maximal pledgeable cash flows of the firm if the debt market participants infer that the speculator receives $\omega=b$ (or $\omega=o$ or $g$ ). Thus, the firm cannot (or can) roll over the debt in the former (latter) case. Furthermore, in the former case, it follows from the assumption of $C_{2}^{b}<L$ that the initial lender prefers to force the firm into liquidation rather than renegotiating with it. If $C_{1}+C_{2}^{o}<R$, then $R$ is larger than the maximal pledgeable cash flows of the firm if the debt market participants infer that the speculator receives $\omega=b$ or $o$. Thus, the firm fails to roll over the debt in these cases. However, if liquidation or an out-of-court restructuring occurs in these cases, the market maker using the same inference can set the CDS price exactly equal to the ex post amount that the protection buyer can receive. ${ }^{13}$ Conversely, when debt market participants infer that the speculator receives $\omega=g$, the market maker using the same inference can again set the CDS price exactly equal to the ex post amount that the protection buyer can receive according to whether the rollover, liquidation, or out-of-court restructuring occurs.

\footnotetext{
${ }^{13}$ If the market maker anticipates liquidation, then $p^{C D S}=1$. Alternatively, as out-of-court restructurings are not a credit event, then $p^{C D S}=0$.
} 
As a result, the speculator does not trade in the CDS market because she cannot make any profits irrespective of any signal she receives. Consequently, if $C_{1}+C_{2}^{o}<R$, debt market participants continue to forecast that the firm's expected cash flows at date 2 are $C_{2}^{o}$, because they cannot extract any new information from the CDS price. Hence, the firm always fails to roll over the debt if $C_{1}+C_{2}^{o}<R$. Then, the initial lender prefers to renegotiate with the firm in an out-of-court restructuring or forces the firm into liquidation according to whether $C_{1}+L+x^{\ell} \leq \lambda\left(C_{1}+C_{2}^{o}\right)$ or $C_{1}+L+x^{\ell}>\lambda\left(C_{1}+C_{2}^{o}\right)$ because the expected payoff of the initial lender at date 1 in renegotiation (or liquidation) is $\lambda\left(C_{1}+C_{2}^{o}\right)$ (or $C_{1}+L+x^{\ell}$ ) in this case.

\subsection{CDS market equilibrium.-}

I first discuss the speculator's order flow in the CDS market. To this end, I assume the following out-of-equilibrium belief of the market maker: anticipating the initial lender's trading strategy $x^{\ell}$, the market maker infers that any deviation of the total order flow $x$ from $\left\{x^{\ell}+n, x^{\ell}, x^{\ell}-n\right\}$ must come from the speculator rather than the initial lender, without changing the market maker's belief about the relative likelihood that the speculator has an informative or uninformative signal. Furthermore, I assume that the market maker believes that if the speculator trades, any quantity other than $n$ is ordered by the speculator who would otherwise have traded $n$ in the same direction. ${ }^{14}$ Then, as in the Kyle (1985) model, the speculator needs to camouflage the information-based trade by mimicking the trades of noise traders to compensate for the information acquisition cost. Thus, the speculator's trade is constrained to be $x^{s} \in\{+n,-n\}$; otherwise, the market maker could extract the speculator's private information when rationally anticipating the initial lender's choice of trading strategy. ${ }^{15}$ This trading strategy for the speculator implies that the total trade order flow minus the initial lender's trade order flow, $x^{s}+x^{n}$, can take only three values $\{+2 n, 0,-2 n\}$ if the speculator trades. However, if $x^{s}+x^{n} \in\{+n,-n\}$, the market maker

\footnotetext{
${ }^{14}$ Because the market maker anticipates the initial lender's trading strategy $x^{\ell}$, the market maker can infer the quantity of the speculator's order unless $x=x^{\ell}$.

${ }^{15}$ The initial lender has chosen the trading strategy of the CDS before the CDS price is determined or at the same time as when the speculator can trade. Thus, without loss of generality, the trading strategy of the initial lender is discussed in the next subsection.
} 
can infer that the speculator is not trading. In the next subsection, under such an outof-equilibrium belief of the market maker, I show that the initial lender has no incentive to deviate from the equilibrium contracting and trading strategy. Hence, even though the market maker cannot identify who submits the order, the market maker's information set is essentially equivalent to the initial lender's.

After the debt contract is signed at date 0 , the speculator chooses an order flow by taking the debt contract as given. The speculator's trading strategy affects the market maker's and debt market participants' inferences about the speculator's received signal. Then, I obtain the following lemma.

Lemma 2: (i)(a) Suppose that $R \leq C_{1}+C_{2}^{o}$. Then, the speculator's trading strategy is $x^{s}$ $=+n$ if $\omega=b, x^{s}=-n$ if $\omega=g$, and $x^{s}=0$ if $\omega=o$.

(b) Suppose that $C_{1}+C_{2}^{o}<R$. Then, the speculator does not incur any information acquisition costs. As a result, the speculator does not trade: $x^{s}=0$ for any $\omega \in\{b, o, g\}$.

(ii) The market maker and debt market participants infer that $\omega=b$ if $x^{s}+x^{n}=+2 n, \omega$ $=g$ if $x^{s}+x^{n}=-2 n$, and $\omega=o$ if $x^{s}+x^{n} \in\{+n, 0,-n\}$.

Intuitively, suppose that $R \leq C_{1}+C_{2}^{o}$. Then, rationally anticipating the initial lender's decision at rollover (see Lemma 1(i) and (ii)), the speculator purchases the CDS when $\omega=b$, sells the CDS when $\omega=g$, and does not trade when $\omega=o$. However, suppose that $C_{1}+C_{2}^{o}$ $<R$. Then, the speculator does not trade any amount of the CDS, because the firm always fails to roll over the debt in this case (see Lemma 1(iii)) and the market maker facing such an inference can set the CDS price equal to the ex post amount that the protection buyer can receive. Given the above trading strategies of the speculator according to the size of $R$, the market maker infers that both the speculator and the noise traders are buying when $x^{s}+$ $x^{n}=+2 n$, and are selling when $x^{s}+x^{n}=-2 n$. In these two cases, the speculator's private information is revealed by the trade orders. Thus, the speculator cannot obtain any profits from trading. However, if $x^{s}+x^{n}=0$, the speculator can earn positive profits from trading because the market maker cannot infer the position of the speculator's order. Finally, if $x^{s}$ $+x^{n} \in\{+n,-n\}$, the speculator is not trading. Thus, $x^{s}+x^{n}$ is not informative about $\omega$. 
The following lemmas represent the probabilities that the market maker and debt market participants infer $\omega \in\{b, o, g\}$ in the CDS market, and specify the equilibrium price of the $\mathrm{CDS}, p^{c d s *}$.

Lemma 3: (i) Suppose that $R \leq C_{1}+C_{2}^{o}$.

(a) The probability that the market maker and debt market participants infer $\omega=b$ is $\frac{\alpha \theta}{2}$.

(b) The probability that the market maker and debt market participants infer $\omega=o$ is $1-\frac{\alpha}{2}$.

(c) The probability that the market maker and debt market participants infer $\omega=g$ is $\frac{\alpha(1-\theta)}{2}$.

(ii) Suppose that $C_{1}+C_{2}^{o}<R$. The probability that the market maker and debt market participants infer $\omega=o$ is 1 .

Lemma 4: (i) Suppose that $R \leq C_{1}+C_{2}^{o}$. Then,

$$
p^{c d s *}=\left\{\begin{array}{cc}
1 & \text { if } x^{s}+x^{n}=+2 n, \\
0 & \text { if } x^{s}+x^{n}=-2 n, \\
\theta & \text { if } x^{s}+x^{n} \in\{+n, 0,-n\} .
\end{array}\right.
$$

(ii) Suppose that $C_{1}+C_{2}^{o}<R$. Then, $p^{\text {cds* }}=0$.

Suppose that $R \leq C_{1}+C_{2}^{o}$. Then, by rationally anticipating the initial lender's decision at rollover at date 1, the market maker is able to infer the speculator's private information completely if $x^{s}+x^{n} \in\{2 n,-2 n\}$. Then, $p^{c d s *}$ is exactly equal to the ex post CDS payment received by the protection buyer. However, the market maker cannot infer the speculator's trading position if $x^{s}+x^{n} \in\{+n, 0,-n\}$. Then, $p^{c d s *}$ is equal to the expected value of the CDS payment received by the protection buyer under the initial belief. In contrast, suppose that $C_{1}+C_{2}^{o}<R$. Then, as verified in Proposition 2 in the next subsection, the initial lender always renegotiates with the firm in an out-of-court restructuring. Thus, $p^{c d s *}$ must be equal to zero, as a result of there being no credit event.

Using Lemmas 2(i), 3, and 4, I derive the speculator's optimal choice of $\alpha$, that is, $\alpha^{*}$.

Lemma 5: $\alpha^{*}=c^{-1}(\theta(1-\theta) n)$ if the speculator incurs information acquisition costs.

No agents other than the speculator can observe the speculator's choice of $\alpha$. However, 
they can form a consistent conjecture about it, given the speculator's cost function.

\subsection{Optimal debt contract and credit protection chosen by the initial lender.-}

Because the initial lender chooses her level of credit protection at date 0 before the CDS price is determined or at the same time as when the speculator can trade, I assume that the initial lender selects the debt contract and the credit protection at date 0 before the CDS price is determined. In addition, I also impose the following assumption.

Assumption 1: $\frac{\alpha^{*} \theta}{2}\left(C_{2}^{o}-C_{2}^{b}\right)>(1-\lambda)\left(C_{1}+C_{2}^{o}\right)$.

This assumption implies that [probability of $\omega=b$ being inferred] $\times[$ difference between the firm's expected date 2 cash flows at $\omega=o$ and at $\omega=b]$ is larger than the renegotiation costs at $\omega=o,(1-\lambda)\left(C_{1}+C_{2}^{o}\right)$. Using $C_{2}^{o}=\theta C_{2}^{b}+(1-\theta) C_{2}^{g}$, Assumption 1 can be rewritten as $\left[\frac{\alpha^{*} \theta}{2}-(1-\lambda)\right](1-\theta) C_{2}^{g}>\theta\left[\frac{\alpha^{*}(1-\theta)}{2}+(1-\lambda)\right] C_{2}^{b}+(1-\lambda) C_{1}$. Thus, this assumption is likely to hold if (i) the renegotiation cost per a given level of cash flows, (1 $-\lambda$ ), is sufficiently small, or (ii)(a) if the probability of $\omega=b$ being inferred, $\frac{\alpha^{*} \theta}{2}$, is larger than $1-\lambda$, and (b) the date 2 cash flows at $\omega=g, C_{2}^{g}$, are sufficiently large.

As the CDSs are actuarially fairly priced in equilibrium, $p^{c d s}$ equals the expected payment the protection seller has to pay to the protection buyer. In particular, when determining $p^{c d s}$, the market maker rationally anticipates the initial lender's action regarding the choice of renegotiation or forcing liquidation at date 1 if the firm cannot roll over the debt. Hence, except for the information transmission role, the only effect of CDS protection in this model is to increase the initial lender's bargaining position in renegotiation: to induce her to accept a renegotiation offer, the firm needs to compensate her for the CDS payment she could collect by forcing the firm into liquidation. This implies that if the CDSs are actuarially fairly priced, their ex ante net value to the initial lender comes only from strengthening her bargaining power in situations where the CDS payment is not triggered.

Thus, when calculating the initial lender's ex ante expected payoff at date 0, I only need to consider the effect of the CDS in the state in which an out-of-court restructuring occurs, because in terms of the agents' expectations at date 0 , the CDS price $p^{c d s}$ will exactly offset 
the CDS payment received by the protection buyer. For simplicity, if the initial lender's ex ante expected payoff at date 0 is independent of her choice of the CDS protection level, I assume that the initial lender's trade order for the CDS is equal to $0 .{ }^{16}$

Now, I obtain the following proposition.

Proposition 2: The optimal debt contract and credit protection chosen by the initial lender are characterized as follows. Note that there exists a threshold $\Psi\left(>C_{2}^{b}\right)$, where $\Psi \equiv$ $\frac{\left(\frac{\alpha^{*} \theta}{2}+\lambda-1\right) C_{2}^{o}-(1-\lambda) C_{1}}{\frac{\alpha^{*} \theta}{2}}$.

(i) Suppose that $\Psi \geq L$. Then,

$$
\begin{gathered}
R>C_{1}+C_{2}^{o}, \\
x^{\ell}=\lambda C_{2}^{o}-(1-\lambda) C_{1}-L>0 .
\end{gathered}
$$

In this case, because the speculator does not trade in the CDS market, the debt market participants always infer $\omega=o$. As a result, the initial lender renegotiates with the firm in an out-of-court restructuring. The initial lender's ex ante expected payoff at date 0 is $\lambda\left(C_{1}\right.$ $\left.+C_{2}^{o}\right)-F$, and the firm value at the beginning of date 0 is $\lambda\left(C_{1}+C_{2}^{o}\right)-F$.

(ii) Suppose that $L>\Psi$. Then,

$$
\begin{gathered}
R=C_{1}+C_{2}^{o}, \\
x^{\ell}=0 .
\end{gathered}
$$

In this case, the speculator trades in the CDS market. The optimal debt contract and credit protection can implement the following policy at rollover: the initial lender forces the firm into liquidation if the debt market participants infer $\omega=b$, whereas the firm rolls over the debt if the debt market participants infer $\omega=o$ or $g$. The initial lender's ex ante expected payoff at date 0 is $C_{1}+\frac{\alpha^{*} \theta}{2} L+\left(1-\frac{\alpha^{*} \theta}{2}\right) C_{2}^{o}-F$, and the firm value at the beginning of date 0 is $C_{1}+\frac{\alpha^{*} \theta}{2} L+\left(1-\frac{\alpha^{*}}{2}\right) C_{2}^{o}+\frac{\alpha^{*}(1-\theta)}{2} C_{2}^{g}-F$.

\footnotetext{
${ }^{16}$ The main results are unaffected even if the initial lender chooses a different level of credit protection in equilibrium. The essential point is that the market maker can predict the initial lender's choice of CDS protection when the CDS is priced in the CDS market. There are many reasons why CDS contracts are nonredundant securities. For example, CDSs have an impact on banks' incentives to monitor and to improve risk sharing, or have lower trading costs than bonds (see Duffee and Zhou, 2001; Parlour and Plantin, 2008; and Oehmke and Zawadowski, 2015). Introducing these can explicitly determine the optimal level of CDS protection.
} 
Several remarks are in order. First, compared to Proposition 1, Proposition 2 implies that even though the empty creditor problem prevails, the introduction of CDS protection prevents the liquidation of the firm on the date of debt rollover and invokes renegotiation in an out-of-court restructuring at date 1 if the liquidation value is not sufficiently large. However, compared to Proposition 1, Proposition 2 also indicates that if the liquidation value is sufficiently large, the introduction of CDS protection implements the following policy at rollover: the initial lender forces the firm into liquidation on the date of debt rollover only if the debt market participants infer $\omega=b$, but allows the firm to roll over the debt if the debt market participants infer $\omega=o$ or $g$. However, in the absence of CDS, the firm always rolls over the debt; thus, neither liquidation nor out-of-court restructuring at date 1 occurs. Hence, in my model, the introduction of CDS protection leads to the increased likelihood of out-of-court restructuring (or bankruptcy) on the date of debt rollover if the liquidation value is not (or is) sufficiently large.

Second, although Proposition 2 suggests that creditor protection of the initial lender is zero if the liquidation value is sufficiently large, this depends on the assumption that her trade order for the CDS is zero if her ex ante expected payoff at date 0 is independent of her choice of the CDS protection level. Because there are many reasons why CDS contracts are nonredundant securities, this assumption does not necessarily exclude empty creditors (that is, holders of debt and CDSs) when the liquidation value is sufficiently large.

Third, the condition of $\Psi \geq L$ can be rewritten as $\frac{\alpha^{*} \theta}{2}\left(C_{2}^{o}-L\right) \geq(1-\lambda)\left(C_{1}+C_{2}^{o}\right)$. Hence, Proposition 2 also states that out-of-court restructuring arises if the potential ex ante expected gains at date 0 for the initial lender from avoiding bankruptcy when the debt market participants may infer $\omega=b$ are larger than the renegotiation costs at $\omega=o$.

Fourth, under the out-of-equilibrium belief of the market maker assumed at the beginning of Subsection 5.2, the initial lender has no incentive to deviate from the optimal debt contract and credit protection given in Proposition 2 because such deviation merely reduces the ex ante expected payoff of the initial lender at date 0 . Note that the initial lender has chosen the trading strategy of the CDS before the CDS price is determined or at the same time the 
speculator can trade.

Intuitively, suppose that the initial lender offers $R \leq C_{1}+C_{2}^{o}$. Then, the CDS price can be informative because the speculator trades in the CDS market, as indicated in Lemma 2(i)(a). Under the assumption of $C_{2}^{o}>L>C_{2}^{b}$, to maximize the ex ante expected payoff at date 0 , the initial lender sets $R=C_{1}+C_{2}^{o}$ and $x^{\ell}=0$, and either forces the firm into liquidation if the debt market participants infer $\omega=b$, or allows the firm to roll over the debt if the debt market participants infer $\omega=o$ or $g$. However, under the assumption of $\lambda\left(C_{1}+\right.$ $\left.C_{2}^{o}\right)>C_{1}+L$, the initial lender may have an incentive to raise the face value of the debt beyond $C_{1}+C_{2}^{o}$ (that is, $\left.R>C_{1}+C_{2}^{o}\right)$ and the level of credit protection from 0 to $\lambda C_{2}^{o}-(1$ $-\lambda) C_{1}-L>0$ in order to improve her bargaining position in a renegotiation. Indeed, the initial lender will always do so if the increased level of credit protection increases her ex ante expected payoff at date 0 when renegotiating with the firm in an out-of-court restructuring, relative to that attained when rolling over the debt contract. This possibility will occur, although she must lose not only some part of her renegotiation surplus due to renegotiation costs, but also the opportunity of learning new information about the firm's expected date 2 cash flows because there will be no trading by the speculator for $R>C_{1}+C_{2}^{o}$ (see Lemma 2(i)(b)). More specifically, this possibility arises if the potential ex ante expected gains at date 0 for the initial lender from avoiding bankruptcy when the debt market participants may infer $\omega=b$ outweigh the losses from renegotiation, $\frac{\alpha^{*} \theta}{2}\left(C_{2}^{o}-L\right) \geq(1-\lambda)\left(C_{1}+C_{2}^{o}\right)$, that is, $\Psi \geq L$.

Comparing Propositions 1 and 2, I can evaluate the effect of CDS introduction on the efficiency of the equilibrium. To this end, even though the benefits and costs in the CDS market must be considered, I only need to consider the effect of CDS introduction on [firm value at date 0$]-\left[\right.$ the speculator's information acquisition cost] because the CDS price $p^{c d s}$ is equal to the expected value of the CDS payment received by the protection buyer under the initial belief.

Now, I obtain the following proposition.

Proposition 3: (i) If $\Psi \geq L, C D S$ introduction impairs the efficiency of the equilibrium. 
(ii) If $L>\Psi, C D S$ introduction impairs (improves) the efficiency of the equilibrium if $c\left(\alpha^{*}\right)$ $>(\leq) \frac{\alpha^{*} \theta}{2}\left(L-C_{2}^{b}\right)$. In particular, if $c(\alpha)=\frac{1}{2} \eta(\alpha)^{2}, C D S$ introduction impairs (improves) the efficiency of the equilibrium if $(1-\theta) n>(\leq) L-C_{2}^{b}$.

Proposition 3 means that if the liquidation value is not sufficiently large, the introduction of CDS impairs the efficiency of the equilibrium. Otherwise, CDS introduction impairs (or improves) the efficiency of the equilibrium if the speculator's information acquisition costs are sufficiently (or not sufficiently) large. In the latter case, if $c(\alpha)=\frac{1}{2} \eta(\alpha)^{2}$, CDS introduction is more likely to impair (or improve) the efficiency of the equilibrium if the trading volume of noise traders, $n$, is larger (or smaller) and/or if the initial belief in the probability of the good state, $1-\theta$, is larger (or smaller). The increase in $n$ can be interpreted as an increase in liquidity in the CDS market, whereas the increase in $\theta$ can be interpreted as a more pessimistic initial belief in profitability uncertainty. Thus, Proposition 3 implies that if the liquidation value is sufficiently large, the inception of CDS markets is more likely to impair (or improve) the efficiency of the equilibrium if the CDS market is more (less) liquid and/or if the initial belief in profitability uncertainty is more (less) optimistic. These results are novel because no previous theoretical studies examine the effect of CDS introduction on the efficiency of equilibrium given the interaction between the informativeness of market trading in CDS markets and the empty creditor problem with debt rollover.

Intuitively, if the CDS price cannot be informative because the speculator does not trade in the CDS market when $\Psi \geq L$, CDS introduction induces the initial lender to renegotiate with the firm in an out-of-court restructuring at all times. Then, CDS introduction decreases the firm's value by $\lambda\left(C_{1}+C_{2}^{o}\right)-F$ at the beginning of date 0 . The reason is that CDS introduction additionally involves renegotiation costs, $(1-\lambda)\left(C_{1}+C_{2}^{\circ}\right)$, because the initial lender attempts to attain the maximal pledgeable cash flows of the firm $\lambda\left(C_{1}+C_{2}^{o}\right)$ by renegotiating with the firm in an out-of-court restructuring, although the firm value at date $0, C_{1}+C_{2}^{o}-F$, can be achieved without renegotiation costs by allowing the firm to roll over the debt in the absence of CDS markets. Hence, CDS introduction impairs the efficiency of the equilibrium. On the other hand, if the CDS price can be informative because the 
speculator trades in the CDS market when $L>\Psi$, CDS introduction forces the firm into liquidation when the debt market participants infer $\omega=b$, and allows the firm to roll over the debt when the debt market participants infer $\omega=o$ or $g$. Then, in the presence of CDS markets, the firm value at the beginning of date 0 increases from $C_{1}+C_{2}^{o}-F$ to $C_{1}+\frac{\alpha^{*} \theta}{2} L+\left(1-\frac{\alpha^{*}}{2}\right) C_{2}^{o}+\frac{\alpha^{*}(1-\theta)}{2} C_{2}^{g}-F$ because of $\theta L+(1-\theta) C_{2}^{g}>C_{2}^{o}$ from $L>$ $C_{b}$. However, CDS introduction still impairs the efficiency of equilibrium if the speculator's information acquisition costs are large $\left(c\left(\alpha^{*}\right)>\frac{\alpha^{*} \theta}{2}\left(L-C_{2}^{b}\right)\right)$. If $c(\alpha)=\frac{1}{2} \eta(\alpha)^{2}$, an increase in $n$ and/or $\theta$ induces the speculator to improve the informativeness of the received signal, $\alpha$, and further raises the information acquisition costs, $c(\alpha)$, incurred by the speculator. Hence, the inception of CDS markets is more likely to impair the efficiency of the equilibrium if $n$ and/or $\theta$ is larger.

Combining Propositions 2 and 3, I derive the following theoretical implication. If early liquidation is inefficient when there is no additional information, contrary to the empty creditor argument, the introduction of CDS protection prevents firm bankruptcy and causes renegotiation in an out-of-court restructuring at debt rollover by inducing the initial lender to choose an initial debt contract that generates opacity about the firm's date 2 cash flows, if the liquidation value is not sufficiently large. In addition, the introduction of CDS protection impairs the efficiency of equilibrium and debt financing from the ex ante viewpoint. However, if the liquidation value is sufficiently large, the introduction of CDS protection increases the possibility of firm bankruptcy and is more likely to impair (improve) the efficiency of equilibrium and debt financing from the ex ante viewpoint if the CDS market is more (less) liquid and/or if the initial belief in profitable uncertainty is more (less) optimistic.

The more transparent information revelation in the CDS market enables the initial lender to liquidate the firm with low cash flows efficiently at debt rollover. However, if the liquidation value is not sufficiently large, the more transparent information does not maximize the ex ante expected payoff of the initial lender at date 0 , when the increased level of credit protection improves her bargaining position in renegotiation and therefore increases her ex ante expected payoff at date 0 from renegotiating the debt contract relative to that from 
rolling over the debt contract. This implies that the initial lender prefers to prevent the speculator from trading and producing transparent information in the CDS market, by designing an initial debt contract that improves the relative bargaining position of the initial lender in renegotiation. However, if the liquidation value is sufficiently large, the initial lender prefers to induce the speculator to trade and produce transparent information in the CDS market, by adjusting the debt contract. This can be interpreted such that the initial lender can commit to choosing the ex post efficient decision at debt rollover by designing the debt contract appropriately at date 0. Then, the debt contract with CDS protection acts as a commitment device for the initial lender to liquidate the firm with low cash flows efficiently if the liquidation value is sufficiently large and the information transmission role in the CDS market is important.

In contrast, Bolton and Oehmke (2011), who do not consider the information transmission role of the CDS market, suggest that if the liquidation value is not sufficiently large, the introduction of CDS protection leads to either efficient out-of-court restructuring or inefficient firm bankruptcy, even in the situation in my paper in which there is no strategic default and the firm can always finance investment by signing a debt contract appropriately [see Proposition 5 and Corollary 4 in Bolton and Oehmke (2011)]. This difference stems from their assumption that the realization of the project cash flows at date 2 is fully revealed to the firm at date 1 and is verified by the firm and its initial lenders at date 1 through paying a verification cost. Thus, in their model, even though the initial lenders purchase a high level of CDS protection so that renegotiation cannot occur when a low cash flow realization at date 2 is revealed at date 1 , the firm can compensate the initial lenders for the high level of CDS payment to induce them to accept a renegotiation offer when a high cash flow realization at date 2 is revealed at date 1 . As a result, it is probable that inefficient firm bankruptcy occurs with a high level of CDS protection.

In contrast, in my paper, the realization of the project cash flows at date 2 can be inferred at date 1 by all the agents excepting the speculator only from information in the CDS market. Hence, it is probable that neither the market maker nor the debt market participants at date 
1 can precisely predict the realization of the date 2 cash flows. In particular, if the liquidation value is not sufficiently large, the potential ex ante expected gains at date 0 from avoiding bankruptcy for the initial lender are larger than the losses from any renegotiation costs because the debt market participants cannot extract any new information from the CDS price at date 1 in this case. Accordingly, in my setting the initial lender always prefers out-of-court restructuring to firm bankruptcy in this case.

My results also provide some interesting implications for the limiting case where CDS markets do not exist. In this situation, on the one hand, the debt market participants may correctly anticipate the firm's future cash flows when CDS markets are introduced. On the other hand, the introduction of CDS markets may cause firm value-reducing out-of-court restructuring as a result of the initial lender's optimal choice of credit protection. The latter possibility arises if the speculator in the CDS market does not trade for the high face value of the debt because the market maker then predicts that the firm always fails to roll over this debt. This trade-off between the informativeness of market trading in CDS markets and the possibility of firm value-reducing out-of-court restructuring under debt rollover is intriguing given the current regulatory debate on CDSs.

Asriyan, Fuchs, and Green (2017) investigate informational spillovers in a dynamic setting with correlated assets owned by privately informed sellers. As a trade in one asset can provide information about the value of other assets in their model, the endogenously determined informational content of trading behavior leads to multiple equilibria when assets are sufficiently correlated. In my model, the debt and the CDS are closely correlated. However, information is produced only in the CDS, not the debt. Thus, in the present model the equilibrium is uniquely determined.

The other empirical and policy implications are discussed in Subsections 6.2 and 6.3.

\subsection{Comparative statics.-}

I first assume that the informativeness of the signal received by the speculator, $\alpha$, is exogenously given, and discuss how the firm's policy at debt rollover is affected by the variation of $\alpha$; the initial belief in the probability of the bad signal, $\theta$; the renegotiation cost 
per a given level of the cash flow, $1-\lambda$; the liquidation value, $L$; and the date 1 cash flows, $C_{1}$. Then, I analyze the effects of varying $\theta$ and the trading volume of noise traders, $n$, on the firm's policy at debt rollover when $\alpha$ is endogenously determined. These comparative static studies lead to new insights because no existing theoretical research discusses the comparative static analysis given the link between the informativeness of market trading in CDS markets and the empty creditor problem under debt rollover.

\subsubsection{Comparative statics when $\alpha$ is exogenously given Now, I obtain:}

Proposition 4: Suppose that $\alpha$ is exogenously given. Then, out-of-court restructuring is more likely to arise in equilibrium if $\alpha$ is larger, $\lambda$ is larger, $L$ is smaller, and $C_{1}$ is smaller. In addition, if $1-\lambda>\frac{\alpha \theta^{2}}{2}$, out-of-court restructuring is more likely to occur in equilibrium if $\theta$ is larger.

If $\alpha$ is exogenously given, Proposition 4 means that out-of-court restructuring is more likely to arise when the informational efficiency is higher ( $\alpha$ is higher), the reorganization cost per a given level of cash flows is smaller ( $\lambda$ is larger), the liquidation value is smaller $(L$ is smaller), and the date 1 cash flows are smaller $\left(C_{1}\right.$ is smaller). Furthermore, Proposition 4 also indicates that if the reorganization cost per a given level of cash flows is not sufficiently

small $\left(1-\lambda>\frac{\alpha \theta^{2}}{2}\right)$, out-of-court restructuring is more likely to arise when the initial belief is more pessimistic ( $\theta$ is higher).

Intuitively, I begin with the situation of Proposition 2(ii), in which the optimal contract and initial credit protection force the firm into liquidation only if the debt market participants infer $\omega=b$, but allow the firm to roll over the debt if the debt market participants infer $\omega$ $=o$ or $g$. Then, given Lemma 3, an increase in $\alpha$ increases the probability that the initial lender liquidates the firm at $L$, while decreasing the probability that the firm continues and generates the expected cash flows $C_{2}^{o}$ at date 2. Thus, it follows from $C_{2}^{o}>L$ that an increase in $\alpha$ decreases the initial lender's ex ante expected payoff at date 0 under the rollover/liquidation policy of Proposition 2(ii). On the other hand, an increase in $\alpha$ does not affect the initial lender's ex ante expected payoff at date 0 in an out-of-court restructuring 
(see Proposition 2(i)). These arguments show that out-of-court restructuring is more likely to occur when the informational efficiency increases.

Similarly, given Lemma 3 , an increase in $\theta$ increases the probability that the initial lender liquidates the firm at $L$, while decreasing not only the firm's ex ante expected cash flows of date $2\left(C_{2}^{o} \equiv \theta C_{2}^{b}+(1-\theta) C_{2}^{g}\right)$ directly, but also the probability that the firm continues and generates the expected cash flows $C_{2}^{o}$ at date 2 . Because $C_{2}^{o}>L$, these effects decrease the initial lender's ex ante expected payoff at date 0 under the rollover/liquidation policy of Proposition 2(ii). However, an increase in $\theta$ also reduces the initial lender's ex ante expected payoff at date 0 in any out-of-court restructuring because of a decrease in $\lambda C_{2}^{o}$ (see Proposition 2(i)). The reduction effect on the initial lender's ex ante expected payoff at date 0 is smaller under the out-of-court restructuring policy than under the rollover/liquidation policy of Proposition 2(ii) if the renegotiation cost per a given level of the cash flow, $1-\lambda$, is not sufficiently small. Thus, if the renegotiation cost per a given level of the cash flow is not sufficiently small, out-of-court restructuring is more likely to arise the more pessimistic is the initial belief about the firm's future revenues.

With regard to the other three parameters, a larger $\lambda$, a smaller $L$, and a smaller $C_{1}$ all increase the initial lender's ex ante expected payoff at date 0 under the out-of-court restructuring policy relative to the rollover/liquidation policy of Proposition 2(ii). Hence, out-of-court restructuring is more likely the smaller is the reorganization cost, the liquidation value, and the date 1 cash flows.

The comparative static result on the informational efficiency $\alpha$ has an interesting implication: the inefficiency caused by the debt contract from the viewpoint of firm value maximization can be increased if the informational efficiency improves. Paradoxically, the greater likelihood of an informative signal is more likely to force the initial lender to select the inefficient out-of-court restructuring policy, although it is more likely to induce the initial lender to liquidate the firm with low cash flows under the rollover/liquidation policy of Proposition 2(ii). Indeed, for the initial lender who chooses the rollover/liquidation policy of Proposition 2(ii), the greater likelihood of an informative signal increases the potential ex 
ante expected gains at date 0 from avoiding bankruptcy, relative to the losses from renegotiation, even though it is possible that the debt market participants infer $\omega=b$. Hence, the more likely the speculator is to receive an informative signal, the more likely out-of-court restructuring is to occur. The result that superior informational efficiency is more likely to cause inefficient out-of-court restructuring in equilibrium depends on the feedback effect created by the interaction between the informativeness of trading in the CDS market and the optimal debt contract and credit protection chosen by the initial lender.

5.4.2. Comparative statics when $\alpha$ is endogenously determined In this subsection, $\alpha$ is endogenously determined as $\alpha^{*}$, which satisfies (A5) in the Appendix. I first analyze how the variation of the initial belief in the probability of the bad signal, $\theta$, and the trade order flow of noise traders, $n$, affects $\alpha^{*}$. Then, using (A5), I obtain the following lemma.

Lemma 6: (i) If $C_{1}+C_{2}^{b}<R \leq C_{1}+C_{2}^{o}$, the endogenously determined $\alpha^{*}$ is increasing (or decreasing) in $\theta$ if $\frac{1}{2}>\theta$ (or $\frac{1}{2}<\theta$ ), and increasing in $n$.

(ii) Irrespective of the size of $R, \alpha^{*}$ is independent of $\lambda, L$, and $C_{1}$.

Now, using Proposition 4 and Lemma 6, I establish the following proposition.

Proposition 5: Suppose that $\alpha$ is endogenously determined as $\alpha^{*}$ given by (6) in the Appendix. Then, out-of-court restructuring is more likely to arise in equilibrium if $n$ is larger, $\lambda$ is larger, $L$ is smaller, and $C_{1}$ is smaller. If $1-\lambda>\frac{\alpha^{*} \theta^{2}}{2}$ and $\frac{1}{2} \geq \theta$, out-of-court restructuring is more likely to arise in equilibrium if $\theta$ is larger.

If $\alpha$ is endogenously determined, Proposition 5 means that an out-of-court restructuring is more likely to occur when the trade order flow of noise traders is larger ( $n$ is larger), the renegotiation cost per a given level of cash flows is smaller $(1-\lambda$ is larger $)$, the liquidation value is smaller ( $L$ is smaller), and the date 1 cash flows are smaller $\left(C_{1}\right.$ is smaller). Furthermore, Proposition 5 indicates that if $1-\lambda$ is not sufficiently small while the initial belief is not so pessimistic, ${ }^{17}$ then out-of-court restructuring is more likely to arise when the initial

\footnotetext{
${ }^{17}$ As verified in Lemma 6 , note that $\alpha^{*}$ is independent of $\lambda$. In addition, Lemma 6 shows that $\alpha^{*}$ is increasing in $\theta$ if $\frac{1}{2} \geq \theta$. Then, the conditions of $1-\lambda>\frac{\alpha^{*} \theta^{2}}{2}$ and $\frac{1}{2} \geq \theta$ are more likely to hold if $1-\lambda$ is not substantially small while $\theta$ is not so large.
} 
belief is more pessimistic ( $\theta$ is higher).

Intuitively, the effects of $\lambda, L$, and $C_{1}$ are not surprising because these variables do not affect the speculator's choice of $\alpha^{*}$. For the comparative statics on $n$, the speculator prefers to trade more as $n$ increases. This implies that the speculator can make more profits by trading, thus raising the informativeness of the received signal, $\alpha^{*}$. However, Proposition 4 shows that raising $\alpha$ is more likely to induce the initial lender to choose an out-of-court restructuring policy. Conversely, an increase in $\theta$ affects the initial lender's decision via two routes: one is the direct effect, and the other is the indirect effect through $\alpha^{*}$. As shown in Proposition 4, the direct effect is more likely to cause out-of-court restructuring if $1-\lambda$ $>\frac{\alpha^{*} \theta^{2}}{2}$. In addition, the indirect effect depends on the variations in the expected marginal profits of the speculator, $\frac{d[\theta(1-\theta) n]}{d \theta}$, thereby raising $\alpha^{*}$ if $\frac{1}{2} \geq \theta$. As discussed above, increasing $\alpha$ is more likely to induce the initial lender to choose an out-of-court restructuring policy. Combining these direct and indirect effects indicates that out-of-court restructuring is more likely to arise if $1-\lambda>\frac{\alpha^{*} \theta^{2}}{2}$ and $\frac{1}{2} \geq \theta$.

The comparative static results on the trading volume of noise traders $n$ have interesting implications. An increase in $n$ can be interpreted as an increase in liquidity in the CDS market. Thus, Proposition 5 implies that a more liquid CDS market is more likely to promote inefficient out-of-court restructuring. A more liquid CDS market also increases transparency and enhances the informational efficiency. However, for the initial lender who chooses the rollover/liquidation policy given by Proposition 2(ii), the greater likelihood of an informative signal increases the potential ex ante expected gains at date 0 from avoiding bankruptcy relative to the losses from renegotiation, even though it is possible that the debt market participants infer $\omega=b$. This effect raises the likelihood of the initial lender choosing out-of-court restructuring.

\section{Extensions and empirical and policy implications}

\subsection{Inside trading in the CDS market.-}

In the corporate bond case, the initial lender can have private inside information if she has 
a close relationship with her borrower. Then, if the initial lender uses this information for speculative purposes in the CDS market, the initial lender can be a speculator, as argued in Acharya and Johnson (2007) and Qiu and Yu (2012). However, I can still obtain my main results even though the initial lender can be a speculator.

I retain the model framework of previous sections, except that the speculator is the initial lender. ${ }^{18}$ In addition, I assume that the initial lender simultaneously chooses a debt contract and submits a CDS trade order $x^{\ell}$ for the credit insurance or protection purpose at the beginning of date 0 . Having observed the debt contract and $x^{\ell}$, the market maker sets a price $p_{-}^{c d s}$ at the beginning of date 0 . I further assume that if the initial lender attempts to acquire information about the firm's date 2 cash flow by expending $c(\alpha)$, she submits a CDS trade order $x^{s}$ for the speculative purpose at the end of date 0 after she receives a private signal $\omega \in\{b, g, o\}$, whereas noise traders also submit their CDS trade orders $x^{n}$ at the end of date 0 . Having observed $x^{s}+x^{n}$, the market maker sets a price $p_{+}^{c d s}$ at the end of date $0 .{ }^{19}$ I assume that the initial lender cannot commit to a specific level of $x^{s}$ at the beginning of date 0 . This assumption may be justified because the choice of $x^{s}$ is delegated to the trading section of the initial lender. Then, given that $x^{s}$ does not affect the initial lender's expected payoff from her relationship lending activity when $R \leq C_{1}+C_{2}^{o}$, she chooses $x^{s}$ to maximize the expected speculation payoff given by (A4) in the Appendix (or the sum of the expected speculation payoff given by (A4) and her expected payoff from her relationship lending activity) when $R \leq C_{1}+C_{2}^{o}$ (or $C_{1}+C_{2}^{o}<R$ ).

Under the assumptions imposed above, I can prove that Lemmas 1-5 still hold, except that the speculator is replaced by the initial lender in Lemmas 1,2 , and 5 ; that $p^{c d s^{*}}$ is replaced with $p_{+}^{c d s^{*}}$ in Lemma 4 , where $p_{+}^{c d s^{*}}$ is the equilibrium price of $p_{+}^{c d s}$; and that Lemma 1 (iii) is restated as follows.

Lemma 1: (iii') Suppose that $C_{1}+C_{2}^{o}<R$. The firm fails to roll over the debt and the

\footnotetext{
${ }^{18}$ Because the private inside information of the initial lender may cause adverse effects only if the other lenders participate in the debt market, I focus on the case in which the initial lender does not assume the rolled over debt.

${ }^{19}$ Even if noise traders participate in the CDS market at both the beginning and the end of date 0 , the results are unchanged as long as the market maker rationally anticipates the rollover and CDS trading strategies of the initial lender.
} 
initial lender renegotiates with the firm in an out-of-court restructuring if $C_{1}+L+x^{\ell}+$ $x^{s} \leq \lambda\left(C_{1}+C_{2}^{o}\right)$ or forces the firm into liquidation if $C_{1}+L+x^{\ell}+x^{s}>\lambda\left(C_{1}+C_{2}^{o}\right)$.

In fact, Lemma 2(i)(b) ensures that $x^{s}=0$ if $C_{1}+C_{2}^{o}<R$, which implies that Lemma 1(iii') is reduced to Lemma 1 (iii).

To develop the analysis, for simplicity I additionally assume that $\alpha$ is exogenously given, and impose the following parametric assumption.

Assumption $1^{\prime}$ : $\frac{\alpha \theta}{2}\left(C_{2}^{o}-C_{2}^{b}\right)>(1-\lambda)\left(C_{1}+C_{2}^{o}\right)+\alpha \theta(1-\theta) n-c(\alpha)$ and $\alpha \theta(1-\theta) n$ $>c(\alpha)$.

Given the remarks below Assumption 1 and the expected speculation payoff (5) for $p_{+}^{c d s^{*}}=\theta$ in the Appendix, Assumption 1' implies that [probability of $\omega=b$ being inferred] $\times[$ difference between the firm's expected date 2 cash flows at $\omega=o$ and at $\omega=b$ ] is larger than the renegotiation costs at $\omega=o,(1-\lambda)\left(C_{1}+C_{2}^{o}\right)$, plus the expected speculative payoff of the initial lender, $\alpha \theta(1-\theta) n-c(\alpha)$. Thus, in addition to the conditions given below Assumption 1, this assumption is likely to hold if the expected speculative payoff of the initial lender is not sufficiently large.

Note that although the initial lender can receive a private signal $\omega \in\{b, g, o\}$ if she attempts to acquire information about the firm's date 2 cash flows by expending $c(\alpha)$, she cannot liquidate the firm at date 1 as long as the firm can roll over their debt. Furthermore, in terms of the agents' expectations at date 0 , the CDS price $p_{-}^{c d s}$ will offset the CDS payment received by the protection buyer; and the expected speculative payoff of the initial lender is fixed because $\alpha$ is exogenously given. Thus, the objective function and the firm's individual rationality constraint of the initial lender's maximization problem are the same for all the cases discussed in Subsection 5.3. As the other debt market participants do not know the private signal received by the initial lender, the equilibrium conditions of the rolled over debt market, (A6) and (A12) in the Appendix, still hold. Thus, I can show that Propositions 2 and 3 still hold if $\Psi$ is replaced with $\Psi^{s} \equiv \frac{\left(\frac{\alpha \theta}{2}+\lambda-1\right) C_{2}^{o}-(1-\lambda) C_{1}-\alpha \theta(1-\theta) n+c(\alpha)}{\frac{\alpha \theta}{2}}$. Note that $\Psi^{s}>$ $C_{2}^{b}$ can be ensured by Assumption 1'. Consequently, I verify that the main results continue to hold even though the initial lender can be a speculator. 


\subsection{Empirical implications.-}

Several researchers investigate how CDSs and empty creditors affect financially distressed firms, but report mixed results. Bedendo et al. (2016) estimate a probit model on the firm's choice between bankruptcy and out-of-court restructuring from an ex post perspective, and find no evidence that firms with CDS contracts are more likely to choose bankruptcy. However, Danis (2017) reports that the rate of participation in distressed exchange offers among bondholders is significantly lower in firms with CDS contracts. Although he does not consider the full set of in- and out-of-court restructuring, his results suggest that firms with CDSs find it difficult to reduce debt in out-of-court restructuring. However, both of these studies use relatively small samples of distressed firms. Exploiting a large sample of both healthy and distressed firms, Subrahmanyam et al. (2014) investigate the effect of CDS introduction on the probability of bankruptcy/downgrade of firms from an ex ante perspective, and suggest that the inception of CDS trading causes a decline in the credit quality and an increase in the probability of bankruptcy of the firms. Given Proposition 2, my results provide a new perspective on these empirical implications in that the introduction of CDSs increases the likelihood of out-of-court restructuring (or bankruptcy) of the firm if the liquidation value is not (or is) sufficiently large. Indeed, the share of non-fixed assets and/or R\&D expenditures is a good proxy for liquidation costs (see Davydenko and Strebulaev, 2007). In addition, firms in some industries, for example, "new economy" industries, such as information technology and bioscience, are more likely to have higher proportions of non-fixed assets and/or R\&D expenditures. Thus, my results show that even though the empty creditor problem prevails, the introduction of CDSs increases the likelihood of out-ofcourt restructuring in firms in new economy industries, such as information technology and bioscience. On the other hand, because of the high share of fixed assets, my results indicate that the introduction of CDSs increases the probability of bankruptcy with subprime MBSs referenced by CDS contracts.

For the question of whether the introduction of CDS markets impairs or improves the efficiency of debt financing, there is again mixed evidence. Ashcraft and Santos (2009) find 
that CDS trading has no significant effect on the cost of debt financing for average firms, although it adversely affects the cost of debt financing for risky and informationally opaque firms. Saretto and Tookes (2013) suggest that firms with traded CDS contracts on their debt maintain high leverage ratios and longer debt maturities. On the other hand, Das et al. (2014) report that following the inception of CDS markets on their debt, bond markets become less efficient, evidence no reduction in pricing errors, and experience no improvement in liquidity. In my paper, it follows from Proposition 3 that the introduction of CDSs impairs the efficiency of debt financing if the liquidation value is not sufficiently large or if the CDS market is sufficiently liquid and/or the initial belief in profitable uncertainty is sufficiently optimistic, although the liquidation value is sufficiently large. Thus, given the argument stated above, my results suggest that the introduction of CDSs impairs the efficiency of debt financing in firms in new economy industries, and that it also impairs the efficiency of debt financing in subprime MBSs referenced by CDSs if the initial belief in profitable uncertainty is sufficiently optimistic.

\subsection{Policy implications.--}

In this paper, I focus on two effects of CDSs. One is that they can cause firm value-reducing rent extraction by protected lenders. The other is the information transmission effect, in which trading in the CDS market reveals information about the firm's future prospects. Hence, in the model, any policy that directly eliminates firm value-reducing rent extraction by protected lenders is recommended unless other countervailing effects arise. ${ }^{20}$ On the other hand, the effect of policy on trade restrictions in the CDS market is subtle. In this subsection, I discuss the regulatory implications by focusing on the policies of increasing liquidity in the CDS market and banning CDS markets.

The policy of increasing liquidity in the CDS market can create greater transparency, thereby inducing speculators to make more profits by trading and to raise the informa-

\footnotetext{
${ }^{20}$ For example, Bolton and Oehmke (2011) discuss the problems of removing creditors' voting rights and making voluntary debt restructuring a credit event. These policies may serve to eliminate inefficient rent extraction by protected lenders, while CDSs cannot serve a positive role by acting as a commitment device for borrowers to pay out cash. Hence, these policies may not be recommended by incorporating the role of CDSs as a commitment device into the present framework.
} 
tiveness of their received signals. However, for lenders, the greater likelihood of receiving an informative signal from the CDS market increases the potential ex ante expected gains from avoiding bankruptcy relative to losses from renegotiation costs when the firm's future prospects may be forecast to be poor. Thus, Proposition 5 suggests that the policy of increasing liquidity in the CDS market is more likely to cause firm value-reducing rent extraction and out-of-court restructuring by protected lenders and would impair the efficiency of debt financing.

The effect of banning CDS markets altogether can be captured by comparing the equilibria with and without a CDS market. It follows from Proposition 3 that CDS introduction is more likely to impair the efficiency of debt financing if the liquidation value is sufficiently small, or if the CDS market is sufficiently liquid and/or the initial belief in profitability uncertainty is sufficiently optimistic, although the liquidation value is not sufficiently small. Hence, banning CDS markets altogether may impair the efficiency of debt financing if the above conditions are satisfied.

\section{Conclusion}

In this paper, I explore the effects of the interaction between the information transmission role and the empty creditor problem of CDSs under debt rollover. Contrary to the empty creditor argument, the introduction of CDS protection increases the possibility of out-ofcourt restructuring if the liquidation value is not sufficiently large. However, if the liquidation value is sufficiently large, the introduction of CDS protection increases the possibility of firm bankruptcy. Furthermore, I also argue that if the liquidation value is not sufficiently large, the introduction of CDS markets impairs the efficiency of equilibrium and debt financing; otherwise, the introduction of CDS markets is more likely to impair (improve) the efficiency of equilibrium and debt financing, as the CDS market is more (less) liquid and/or the initial belief in profitability uncertainty is more (less) optimistic. These findings provide several empirical implications. In particular, they suggest that in firms in new economy industries, the introduction of CDSs increases the likelihood of out-of-court restructuring despite the 
empty creditor problem and thereby raises the inefficiency of debt financing. On the other hand, with the subprime MBSs referenced by CDS contracts, the inception of CDS trading is expected to increase the likelihood of bankruptcy and impair the efficiency of debt financing if the initial belief in profitable uncertainty is sufficiently optimistic.

For the comparative static results, when the informativeness of the signal received by the speculator is determined exogenously, inefficient out-of-court restructuring is more likely to arise when the signal received by the speculator is more informative and when the initial belief is more pessimistic if the renegotiation cost per a given level of cash flows is not sufficiently small. On the other hand, when the informativeness of the signal received by the speculator is endogenously determined, inefficient out-of-court restructuring is more likely to occur when the CDS market is more liquid and when the initial belief is more pessimistic if the reorganization cost per a given level of cash flows is not sufficiently small while the initial belief is not too pessimistic.

My analysis can be used to assess the effect of a number of policy measures. In my model, the policy of increasing liquidity in CDS markets is more likely to cause firm value-reducing rent extraction by protected lenders, which would impair the efficiency of debt financing. On the other hand, banning CDS markets altogether may impair or improve the efficiency of debt financing, because its effect depends on the liquidation value relative to the investment level, the initial belief in the uncertainty of firm profitability, and the liquidity of the CDS markets.

Several researchers argue that limiting the disclosure of information can be optimal (e.g., Pagano and Volpin, 2012; Monnet and Quintin, 2017; and Vanasco 2017). Bigus and Hakenes (2014) suggest that conservative opacity enables relationship lending more effectively than aggressive reporting because overly transparent financial reporting reduces the relationship lender's information rent. Dang et al. (2017) also argue that banks can produce moneylike safe liquidity by keeping detailed information about their loans secret and preventing information acquisition by outsiders. Although my analysis is not concerned with disclosure policy, I show that the optimal debt contract may lower the informativeness of market 
trading in CDS markets, when the increased level of credit protection by CDS improves her bargaining position and raises her ex ante expected payoff in renegotiation. 


\section{Appendix}

Proof of Proposition 1: I first specify the initial lender's maximization problem at date 0 when the firm can roll over its debt at date $1 .{ }^{21}$ It is evident that the initial lender's payoff is $R-F$. Let $R^{\prime}$ denote the face value of the debt rolled over at date 1 . In the absence of CDS markets, none of the agents can receive any new information after the debt contract is signed. Thus, at date 1 , the firm's date 2 cash flows continue to be expected to be $C_{2}^{b}$ $\left(C_{2}^{g}\right)$ with probability $\theta(1-\theta)$. Hence, the firm's expected payoff at date 0 is $\theta \max \left(C_{1}+\right.$ $\left.C_{2}^{b}-R^{\prime}, 0\right)+(1-\theta) \max \left(C_{1}+C_{2}^{g}-R^{\prime}, 0\right)$. The face value of the rolled over debt $R^{\prime}$ is determined by the competitive market. Thus, the payment from the rolled over debt buyer to the initial lender (the price of the rolled over debt), $R$, must be equal to the expected payoff from the rolled over debt:

$$
\theta \min \left(R^{\prime}, C_{1}+C_{2}^{b}\right)+(1-\theta) \min \left(R^{\prime}, C_{1}+C_{2}^{g}\right)=R
$$

Equation (A1) ensures that the initial lender can indirectly determine $R^{\prime}$ by adjusting $R$. Consequently, if the firm can roll over its debt, the initial lender's maximization problem at date 0 is:

$$
\max _{R, R^{\prime}} R-F
$$

subject to $(\mathrm{A} 1)$ and

$$
\theta \max \left(C_{1}+C_{2}^{b}-R^{\prime}, 0\right)+(1-\theta) \max \left(C_{1}+C_{2}^{g}-R^{\prime}, 0\right) \geq 0 .
$$

Here, constraint (A3) is the firm's individual rationality constraint, where the firm's reservation payoff must be larger than or equal to zero.

Solving problem (A2), I now derive the maximal value of the initial lender's expected

\footnotetext{
${ }^{21}$ Even though the initial lender is replaced by a new lender, the following discussion is unchanged. The reason is that the debt contract rolled over at date 1 does not appear in the objective function of the initial lender. This is because the rolled over debt is fairly priced in the competitive market so that the payment from the rolled over debt buyer to the initial lender is exactly equal to the expected payoff from the rolled over debt.
} 
payoff at date 0 when the firm can roll over its debt. Suppose that $R \leq C_{1}+C_{2}^{b}$. In this case, for $R^{\prime}$ that satisfies both (A1) and (A3), the initial lender's expected payoff at date 0 is maximized by $R^{\prime}=R=C_{1}+C_{2}^{b}$. Next, suppose that $C_{1}+C_{2}^{b}<R \leq C_{1}+C_{2}^{\circ}$. In this case, for $R^{\prime}$ that satisfies both (A1) and (A3), the initial lender's expected payoff at date 0 is maximized by $R^{\prime}=C_{1}+C_{2}^{g}$ and $R=C_{1}+C_{2}^{o}$. Note that $C_{2}^{o} \equiv \theta C_{2}^{b}+(1-\theta) C_{2}^{g}$. If $C_{1}+$ $C_{2}^{\circ}<R$, the firm cannot roll over its debt because its maximal pledgeable cash flows at date 1 are $C_{1}+C_{2}^{\circ}$ in the absence of CDS markets. Hence, this case need not to be examined. Now, it is evident from $C_{2}^{o}>C_{2}^{b}$ that the maximal expected payoff of the initial lender at date 0 is given as $C_{1}+C_{2}^{o}-F$ by setting $R^{\prime}=C_{1}+C_{2}^{g}$ and $R=C_{1}+C_{2}^{o}$ when the firm can roll over its debt.

On the other hand, if the firm fails to roll over its debt at date 1 because $R$ is sufficiently large, the initial lender's expected payoff is $(1-q) \lambda\left(C_{1}+C_{2}^{o}\right)-F$ in an out-of-court restructuring, and $\min \left(C_{1}+L, R\right)-F$ in liquidation. Note that the available renegotiation surplus at date 1 in this case is $\lambda\left(C_{1}+C_{2}^{o}\right)$ because none of the agents can receive any new information after the debt contract is signed. Under the assumption of $C_{2}^{o}>L$, I verify the result of this proposition by comparing the above three values of the initial lender's expected payoff at date 0 .

Proof of Lemma 1: Suppose that the debt market participants infer that the speculator receives $\omega \in\{b, g, o\}$. If the firm can roll over debt, and the initial lender with a CDS position $x^{\ell}$ continues to assume the rolled over debt, the initial lender's expected payoff at date 1 is $R+x^{\ell}\left[\operatorname{Pr}\left(C_{2}^{b} \mid \omega\right) \operatorname{Pr}\left(R^{\prime}>C_{1}+C_{2}^{b}\right)+\operatorname{Pr}\left(C_{2}^{g} \mid \omega\right) \operatorname{Pr}\left(R^{\prime}>C_{1}+C_{2}^{g}\right)\right] ;^{22}$ and the firm's expected payoff at date 1 is $\operatorname{Pr}\left(C_{2}^{b} \mid \omega\right) \max \left(C_{1}+C_{2}^{b}-R^{\prime}, 0\right)+\operatorname{Pr}\left(C_{2}^{g} \mid \omega\right) \max \left(C_{1}+C_{2}^{g}-\right.$ $R^{\prime}, 0$ ), where $R^{\prime}$ is the face value of the rolled over debt and $\omega \in\{b, g, o\}$. Note that if the firm cannot repay $R^{\prime}$ at date 2 , the initial lender with a CDS position $x^{\ell}$ who continues to assume the rolled over debt receives the CDS payment $x^{\ell}$.

\footnotetext{
${ }^{22}$ Even though the initial lender continues to assume the rolled over debt, note that her expected payoff at date 1 except for the CDS payment is still $R$. The reason is that the price of the rolled over debt is exactly equal to the expected payoff from the rolled over debt because the rolled over debt is fairly priced in the competitive market.
} 
Even though the firm can roll over the debt when the initial lender does not continue to assume the rolled over debt, both the initial lender's expected payoff at date 1 and the firm's expected payoff at date 1 are given by the same forms as the above case. Note that even in this case, the initial lender with a CDS position $x^{\ell}$ can receive the CDS payment $x^{\ell}$ if the firm cannot repay $R^{\prime}$ at date 2 .

If the firm fails to roll over its debt, and the initial lender with a CDS position $x^{\ell}$ liquidates the firm, the initial lender's payoff at date 1 is $\min \left(C_{1}+L, R\right)+x^{\ell}$ and the firm's payoff at date 1 is $\max \left(C_{1}+L-R, 0\right)$. Note that when liquidation occurs, the initial lender with a CDS position $x^{\ell}$ receives the CDS payment $x^{\ell}$ because liquidation is a credit event.

If the firm fails to roll over debt but the initial lender with a CDS position $x^{\ell}$ renegotiates with the firm in an out-of-court restructuring, any out-of-court restructuring offer must compensate the initial lender for her outside option of forcing the firm into liquidation and collecting the CDS payment. The reason is that the presence of the CDS protection increases the initial lender's bargaining position in renegotiation. As a result, to induce the initial lender to accept a renegotiation offer, the firm needs to compensate her for the CDS payment she could collect by forcing the firm into liquidation. Thus, in the out-of-court restructuring, the initial lender's payoff at date 1 will be $\max \left[(1-q) \lambda\left(C_{1}+C_{2}^{\omega}\right), \min \left(C_{1}\right.\right.$ $\left.+L, R)+x^{\ell}\right]$; and the firm's payoff at date 1 will be $q \lambda\left(C_{1}+C_{2}^{\omega}\right)$ if $(1-q) \lambda\left(C_{1}+C_{2}^{\omega}\right) \geq$ $\min \left(C_{1}+L_{1}, R\right)+x^{\ell}$, and $\max \left(C_{1}+L-R, 0\right)$ if $(1-q) \lambda\left(C_{1}+C_{2}^{\omega}\right)<\min \left(C_{1}+L, R\right)$ $+x^{\ell}{ }^{23}$ Here, $C_{2}^{\omega}$ denotes $C_{2}$ at $\omega \in\{b, g, o\}$. Note that the initial lender cannot receive any CDS payments in the out-of-court restructuring, which is not a credit event. However, if $\min \left(C_{1}+L, R\right)+x^{\ell}$ exceeds the available renegotiation surplus $\lambda\left(C_{1}+C_{2}^{\omega}\right)$, renegotiation becomes totally impossible. Thus, in this case, I can rule out the possibility of renegotiation in an out-of-court restructuring if the firm fails to roll over its debt.

Given the above arguments, I prove statements (i), (ii), and (iii) of Lemma 1 as follows. (i) Regardless of the conjectures of the debt market participants regarding the firm's date 2 cash flows, the maximal pledgeable cash flows of the firm are at least equal to $C_{1}+C_{2}^{b}$. If

\footnotetext{
${ }^{23} \mathrm{I}$ assume that the initial lender chooses to renegotiate with the firm in an out-of-court restructuring when she is indifferent between liquidating or renegotiating with the firm in the out-of-court restructuring.
} 
$R \leq C_{1}+C_{2}^{b}$, then $R$ is smaller than or equal to the least of the maximal pledgeable cash flows of the firm. Hence, the firm can always roll over its debt.

(ii) Suppose that the debt market participants infer that the speculator receives $\omega=b$. If $C_{1}+C_{2}^{b}<R \leq C_{1}+C_{2}^{o}$, then $R$ is larger than the maximal pledgeable cash flows of the firm. Thus, the firm fails to roll over its debt. In addition, under the assumptions of $C_{2}^{b}<L$ and $C_{1}+C_{2}^{b}<R \leq C_{1}+C_{2}^{o}$, renegotiation in an out-of-court restructuring is impossible if $x^{\ell} \geq 0$, because $\min \left(C_{1}+L, R\right)+x^{\ell}$ exceeds the available renegotiation surplus $\lambda\left(C_{1}\right.$ $\left.+C_{2}^{b}\right)$. Thus, the initial lender only forces the firm into liquidation if $x^{\ell} \geq 0$. In fact, the possibility of $x^{\ell}<0$ can be ruled out when $C_{1}+C_{2}^{b}<R \leq C_{1}+C_{2}^{o}$. The reason is as follows. When the debt market participants infer that the speculator receives $\omega=b$, it follows from $C_{2}^{b}<L$ and $C_{1}+C_{2}^{b}<R \leq C_{1}+C_{2}^{o}$ that except for the CDS payment $x^{\ell}$, the initial lender's expected payoff at date 1 in liquidation, $\min \left(C_{1}+L, R\right)$, is always larger than that in renegotiation because the firm's maximal pledgeable cash flows are then $C_{1}+C_{2}^{b}$. Furthermore, when the debt market participants infer that the speculator receives $\omega=o$ or $g$, the firm can always roll over its debt, as shown below. Hence, in view of the specification of the initial lender's expected payoff at date 1 when the firm can roll over its debt (see the first paragraph of the proof of this lemma), the initial lender's expected payoff at date 1 is increasing in $x^{\ell}$ in these inferences. These arguments imply that the initial lender reduces her ex ante expected payoff at date 0 if she chooses $x^{\ell}<0$ when $C_{1}+C_{2}^{b}<R \leq C_{1}+C_{2}^{o}$. Thus, the initial lender sets $x^{\ell} \geq 0$ to avoid renegotiation. Accordingly, I can exclude the possibility of $x^{\ell}<0$.

Next, suppose that the debt market participants infer that the speculator receives $\omega=$ $o$ or $g$. If $C_{1}+C_{2}^{b}<R \leq C_{1}+C_{2}^{o}$, then $R$ is smaller than the least of the maximal pledgeable cash flows of the firm, regardless of whether the debt market participants infer that the speculator receives $\omega=o$ or $g$. Thus, the firm can always roll over its debt in these inferences.

(iii) In this case, I begin by proving that the speculator does not trade any amount of CDS in the CDS market. First, suppose that the debt market participants infer that the speculator 
receives $\omega=b$ or $o$. If $C_{1}+C_{2}^{o}<R$, then $R$ is larger than the maximal pledgeable cash flows of the firm. Thus, the firm fails to roll over its debt in these inferences. As a result, liquidation or renegotiation in an out-of-court restructuring occurs, according to whether or not $\min \left(C_{1}+L, R\right)+x^{\ell}$ exceeds the available renegotiation surplus $\lambda\left(C_{1}+C_{2}^{j}\right)$, for $j=b$ or $o$. However, because the market maker in the CDS market can anticipate this and set the CDS price $p^{c d s}$ to be exactly equal to the ex post CDS payment received by the protection buyer, the speculator in the CDS market cannot earn any profits when the debt market participants infer that the speculator receives $\omega=b$ or $o$ and $C_{1}+C_{2}^{o}<R$.

Now, suppose that the debt market participants infer that the speculator receives $\omega=g$. I first deal with the case of $C_{1}+C_{2}^{o}<R \leq C_{1}+C_{2}^{g}$. Here, the firm can roll over its debt. However, the market maker can anticipate this and set the CDS price $p^{c d s}$ to be exactly equal to the ex post CDS payment received by the protection buyer. Next, I consider the case of $C_{1}+C_{2}^{g}<R$. Then, liquidation or renegotiation in an out-of-court restructuring is chosen, according to whether $\min \left(C_{1}+L, R\right)+x^{\ell}$ exceeds the available renegotiation surplus $\lambda\left(C_{1}\right.$ $+C_{2}^{g}$ ). Once again, the market maker can anticipate this and set $p^{c d s}$ exactly equal to the ex post CDS payment received by the protection buyer. As a result, the speculator in the CDS market cannot earn any profits when the debt market participants infer that the speculator receives $\omega=g$ and $C_{1}+C_{2}^{o}<R$.

Combining these arguments, I verify that the speculator does not incur any information acquisition costs or trade any amount of CDS in the CDS market, because the speculator cannot make any profits. As the debt market participants cannot receive any new information at date 1 , their expectation about $C_{2}$ remains $C_{2}^{o} \equiv \theta C_{2}^{b}+(1-\theta) C_{2}^{g}$. If $C_{1}+C_{2}^{o}<R$, then $R$ is larger than the maximal pledgeable cash flows of the firm. Thus, if $C_{1}+C_{2}^{o}<$ $R$, the firm fails to roll over its debt; and the initial lender renegotiates with the firm in an out-of-court restructuring if $C_{1}+L+x^{\ell} \leq \lambda\left(C_{1}+C_{2}^{o}\right)$ or forces the firm into liquidation if $C_{1}+L+x^{\ell}>\lambda\left(C_{1}+C_{2}^{o}\right)$.

Proof of Lemma 2: (i) The speculator's trading strategy is derived by taking the debt contract as given. Note that $0 \leq p^{c d s} \leq 1$, where the strict inequality holds if the market 
maker does not infer $\omega=b$ or $g$ and if the firm can roll over the debt.

Now, suppose that $R \leq C_{1}+C_{2}^{b}$. Then, Lemma 1(i) shows that the firm can always roll over its debt. Thus, for $\omega=b$, the speculator obtains profits from trading equal to $1-p^{c d s}$ $\left(p^{c d s}-1\right)$, by buying (selling) the CDS, and no profits if she makes no trade. Note that for $\omega=b, 1-p^{c d s}\left(p^{c d s}-1\right)$ is strictly positive (negative) if the market maker does not infer $\omega=b$, and is equal to 0 otherwise. Thus, buying the CDS is the dominant strategy when $\omega$ $=b$. For $\omega=g$, the speculator obtains profits from trading equal to $-p^{c d s}\left(p^{c d s}\right)$ by buying (selling) the CDS, and makes no profits if she does not trade. In this case, however, note that for $\omega=g,-p^{c d s}\left(p^{c d s}\right)$ is strictly negative (positive) if the market maker does not infer $\omega=g$, and is equal to 0 otherwise. Thus, selling the CDS is the dominant strategy when $\omega=g$. For $\omega=o$, the speculator receives no additional information. Because the market maker sets the CDS price $p^{c d s}$ equal to the expected CDS payment received by the protection buyer, the speculator does not trade when $\omega=o$.

Next, suppose that $C_{1}+C_{2}^{b}<R \leq C_{1}+C_{2}^{o}$. Then, Lemma 1(ii) indicates that the lender forces the firm into liquidation if the debt market participants infer that the speculator receives $\omega=b$, whereas the firm can roll over its debt if the debt market participants infer that the speculator receives $\omega=o$ or $g$. Again, for $\omega=b$, the speculator obtains profits from trading of $1-p^{c d s}\left(p^{c d s}-1\right)$ by buying (selling) the CDS, and no profits if she does not trade. Note that for $\omega=b, 1-p^{c d s}\left(p^{c d s}-1\right)$ is strictly positive (negative) if the market maker does not infer $\omega=b$, and is equal to 0 otherwise. Thus, the speculator buys the CDS when $\omega=b$. For $\omega=g$ or $o$, repeating the above argument in the case of $R \leq C_{1}+C_{2}^{b}$, I can show that the speculator sells the CDS when $\omega=g$, but does not trade when $\omega=o$.

Finally, suppose that $C_{1}+C_{2}^{o}<R$. As in the proof of Lemma 1(iii), the speculator does not trade any amount of the CDS, because she cannot make any profits.

Combining these arguments, I verify statement (i) of this lemma. The speculator always buys the $\operatorname{CDS}\left(x^{s}=+n\right)$ for $\omega=b$, always sells the CDS $\left(x^{s}=-n\right)$ for $\omega=g$, and does not trade $\left(x^{s}=0\right)$ for $\omega=o$ if $R \leq C_{1}+C_{2}^{o}$; and does not trade $\left(x^{s}=0\right)$ for any $\omega \in\{b, o, g\}$ if $R>C_{1}+C_{2}^{o}$. 
(ii) Given the trading strategy of the speculator, the market maker infers the total trade order flow minus the initial lender's trade order flow, $x^{s}+x^{n}$, as follows: (a) both the speculator and noise traders are buying when $x^{s}+x^{n}=+2 n$; (b) both the speculator and noise traders are selling when $x^{s}+x^{n}=-2 n$; (c) the position of the speculator's order cannot be inferred when $x^{s}+x^{n}=0$; and (d) the speculator is not trading when $x^{s}+x^{n} \in$ $\{+n,-n\}$. As will be shown in Lemma $4, p^{c d s}$ and $x^{s}+x^{n}$ have a relationship represented by (1). Hence, the market maker and debt market participants can make the inference given by Lemma 2(ii).

Proof of Lemma 3. (i) Suppose that $R \leq C_{1}+C_{2}^{o}$. When the speculator attempts to acquire information, I have assumed that the speculator receives a signal $b(g)$ with probability $\alpha \theta(\alpha(1-\theta))$, while receiving a signal $o$ with probability $1-\alpha$. In addition, I have also assumed that $x^{n}=n(>0)$ with probability $\frac{1}{2}$, and $x^{n}=-n$ with probability $\frac{1}{2}$. Thus, using Lemma 2(i)(a) and 2(ii) gives the probabilities that the market maker and debt market participants infer $\omega=b, o$, or $g$ at date 1 .

(ii) Suppose that $C_{1}+C_{2}^{o}<R$. Then, the speculator does not incur any information acquisition costs or trade any amount of CDS. Using Lemma 2(i)(b) and 2(ii), the probability that the market maker and the debt market participants infer $\omega=o$ is 1 .

Proof of Lemma 4: Suppose that $R \leq C_{1}+C_{2}^{o}$. As Lemma 2(ii) shows that the market maker is able to infer the speculator's private information completely as $b$ (or $g$ ) if $x^{s}+x^{n}$ $=2 n($ or $-2 n)$, the CDS price $p^{c d s}$ is then equal to the ex post CDS payment received by the protection buyer, regardless of the face value of the debt. Thus, it follows from Lemma 1(i)(ii) and the above argument that if $x^{s}+x^{n}=+2 n\left(\right.$ or $\left.x^{s}+x^{n}=-2 n\right)$, the market maker sets $p^{c d s *}=1$ (or $p^{c d s *}=0$ ) by inferring that the speculator's private signal is $b$ (or $g$ ). On the other hand, if $x^{s}+x^{n}=\{+n, 0,-n\}$, the market maker cannot infer the speculator's position from the trade order flow. Because the firm's date 2 cash flows are equal to $C_{2}^{b}\left(C_{2}^{g}\right)$ with probability $\theta(1-\theta)$ under the initial belief in public, it again follows from Lemma 1(i)(ii) that if $x^{s}+x^{n}=\{+n, 0,-n\}$, the market maker sets $p^{c d s *}=\theta$ by inferring that the speculator's private signal is $o$. 
Next, suppose that $C_{1}+C_{2}^{o}<R$. As verified in Proposition 2, the initial lender always renegotiates with the firm in an out-of-court restructuring in this case. Hence, $p^{c d s *}=0$ in this case because the protection seller need not pay anything as a result of there being no credit event.

Proof of Lemma 5: In the proof of Proposition 2, I show that the debt contract with the face value of $R \leq C_{1}+C_{2}^{b}$ is always dominated. Furthermore, Lemma 2(i)(b) indicates that the speculator does not incur any information acquisition costs when $C_{1}+C_{2}^{o}<R$. Hence, I can focus on the case of $C_{1}+C_{2}^{b}<R \leq C_{1}+C_{2}^{o}$. Then, given that the speculator's expected payoff can be positive only when $x^{s}+x^{n}=0$, it is represented by:

$$
\frac{\alpha \theta}{2}\left(1-p^{c d s *}\right) n+\frac{\alpha(1-\theta)}{2} p^{c d s *} n-c(\alpha)
$$

Here, the ex ante probability of the speculator observing $\omega=b$ is $\alpha \theta$. If the speculator observes $\omega=b$, it follows from Lemma 2(i)(a) that the speculator buys the CDS $\left(x^{s}=+n\right)$. Trading profit is then positive only if the trade order does not reveal the speculator's private information $\left(x^{s}+x^{n}=0\right)$, which occurs with probability $\frac{1}{2}$. In this case, the speculator's payoff per unit is $1-p^{c d s *}$. The reason is that the speculator pays the premium $p^{c d s *}$ per unit while receiving 1 per unit because the firm rolls over its debt at date 1 but cannot repay the face value of the rolled over debt at date 2 . On the other hand, the ex ante probability of the speculator observing $\omega=g$ is $\alpha(1-\theta)$. Then, Lemma 2(i)(a) indicates that the speculator sells the CDS $\left(x^{s}=-n\right)$. Trading profit is positive only if $x^{s}+x^{n}=0$, which occurs with probability $\frac{1}{2}$. In this case, the speculator's payoff per unit is $p^{c d s *}$. The reason is that the speculator receives the premium $p^{c d s *}$ per unit while paying nothing because the firm rolls over its debt at date 1 and repays the face value of the rolled over debt at date 2 . For $\omega=$ $o$, Lemma 2(i)(a) suggests that the speculator does not trade. Substituting $p^{c d s *}=\theta$ from (1) into (A4) and differentiating it with respect to $\alpha$ yields:

$$
\theta(1-\theta) n-c^{\prime}(\alpha)=0 .
$$


Thus, I obtain $\alpha^{*}=c^{\prime-1}(\theta(1-\theta) n)$.

Proof of Proposition 2: Given that the ex ante net value of CDS to the initial lender comes entirely from strengthening her bargaining power only in the situation that does not trigger payment of the CDS, the initial lender's maximization problem with respect to the choice of the debt contract and the credit protection is formalized as follows.

Suppose that $R \leq C_{1}+C_{2}^{b}$. Lemma 1(i) implies that the firm can always roll over its debt. Thus, the ex ante expected payoff to the initial lender at date 0 is represented by: ${ }^{24}$

$$
R-F \text {. }
$$

To specify the ex ante expected payoff to the firm at date 0 , let $R^{\prime}$ denote the face value of the debt rolled over at date 1 . The firm's date 2 cash flows are deterministically equal to $C_{2}^{b}\left(C_{2}^{g}\right)$ when the debt market participants infer $\omega=b(\omega=g)$ at date 1 , whereas the firm's date 2 cash flows are equal to $C_{2}^{b}\left(C_{2}^{g}\right)$ with probability $\theta(1-\theta)$ when the debt market participants infer $\omega=o$ at date 1. Then, it follows from Lemmas 1(i) and 3(i) that the firm's ex ante expected payoff at date 0 is:

$$
\begin{aligned}
& \frac{\alpha^{*} \theta}{2} \max \left(C_{1}+C_{2}^{b}-R^{\prime}, 0\right)+\left(1-\frac{\alpha^{*}}{2}\right) \theta \max \left(C_{1}+C_{2}^{b}-R^{\prime}, 0\right) \\
& +\left(1-\frac{\alpha^{*}}{2}\right)(1-\theta) \max \left(C_{1}+C_{2}^{g}-R^{\prime}, 0\right)+\frac{\alpha^{*}(1-\theta)}{2} \max \left(C_{1}+C_{2}^{g}-R^{\prime}, 0\right) \\
& =\theta \max \left(C_{1}+C_{2}^{b}-R^{\prime}, 0\right)+(1-\theta) \max \left(C_{1}+C_{2}^{g}-R^{\prime}, 0\right) .
\end{aligned}
$$

$R^{\prime}$ is determined by the competitive market. As the price of the rolled over debt $R$ must be offset by the expected payoff from the rolled over debt in equilibrium, $R^{\prime}$ must satisfy:

$$
\theta \min \left(R^{\prime}, C_{1}+C_{2}^{b}\right)+(1-\theta) \min \left(R^{\prime}, C_{1}+C_{2}^{g}\right)=R
$$

\footnotetext{
${ }^{24}$ As argued above, in terms of the agents' expectations at date $0, p^{c d s}$ will offset the CDS payment received by the protection buyer. The only effect of CDS protection in this model is to increase the initial lender's bargaining position in renegotiation. Hence, unlike the discussions in Subsection 5.1 and the proof of Lemma 1, which deal with the agents' expectations at date 1, the ex ante expected payoff to the initial lender at date 0 does not include any terms $x^{\ell}$ or $p^{c d s}$ if an out-of-court restructuring does not occur.
} 
Equation (A6) ensures that the initial lender can indirectly determine $R^{\prime}$ by adjusting $R$.

Consequently, the initial lender's maximization problem at date 0 is:

$$
\max _{R \geq 0, R^{\prime} \geq 0} R-F
$$

subject to $(\mathrm{A} 6)$ and

$$
\begin{gathered}
\theta \max \left(C_{1}+C_{2}^{b}-R^{\prime}, 0\right)+(1-\theta) \max \left(C_{1}+C_{2}^{g}-R^{\prime}, 0\right) \geq 0, \\
C_{1}+C_{2}^{b} \geq R .
\end{gathered}
$$

Here, (A8) is the firm's individual rationality constraint, where the firm's reservation payoff must be larger than or equal to zero. (A9) is required under the restriction of $R \leq C_{1}+C_{2}^{b}$.

Next, suppose that $C_{1}+C_{2}^{b}<R \leq C_{1}+C_{2}^{o}$. Lemma 1(ii) indicates that the firm fails to roll over its debt and the initial lender forces the firm into liquidation when the debt market participants infer that the speculator receives $\omega=b$; on the other hand, the firm can roll over its debt when the debt market participants infer that the speculator receives $\omega=o$ or g. Thus, using Lemma 3(i), the ex ante expected payoff to the initial lender at date 0 is given by: $:^{25}$

$$
\frac{\alpha^{*} \theta}{2} \min \left(C_{1}+L, R\right)+\left(1-\frac{\alpha^{*} \theta}{2}\right) R-F
$$

Let $R^{\prime}$ denote the face value of the rolled over debt at date 1 . The firm's date 2 cash flows are equal to $C_{2}^{b}$ with probability $\theta$ (or 0 ) and $C_{2}^{g}$ with probability $1-\theta$ (or 1 ) when the debt market participants infer $\omega=o(\omega=g)$ at date 1. Then, it follows from Lemmas 1(ii) and 3(i) that the firm's ex ante expected payoff at date 0 is:

$$
\begin{aligned}
& \frac{\alpha^{*} \theta}{2} \max \left(C_{1}+L-R, 0\right)+\left(1-\frac{\alpha^{*}}{2}\right) \theta \max \left(C_{1}+C_{2}^{b}-R^{\prime}, 0\right) \\
& +\left(1-\frac{\alpha^{*}}{2}\right)(1-\theta) \max \left(C_{1}+C_{2}^{g}-R^{\prime}, 0\right)+\frac{\alpha^{*}(1-\theta)}{2} \max \left(C_{1}+C_{2}^{g}-R^{\prime}, 0\right)
\end{aligned}
$$

\footnotetext{
${ }^{25}$ See footnote 24 .
} 
$=\frac{\alpha^{*} \theta}{2} \max \left(C_{1}+L-R, 0\right)+\left(1-\frac{\alpha^{*}}{2}\right) \theta \max \left(C_{1}+C_{2}^{b}-R^{\prime}, 0\right)+(1-\theta) \max \left(C_{1}+C_{2}^{g}-R^{\prime}, 0\right)$.

Accordingly, if the firm can roll over its debt, the initial lender's maximization problem at date 0 is:

$$
\max _{R, R^{\prime}} \frac{\alpha^{*} \theta}{2} \min \left(C_{1}+L, R\right)+\left(1-\frac{\alpha^{*} \theta}{2}\right) R-F
$$

subject to:

$$
\begin{gathered}
\frac{\alpha^{*} \theta}{2} \max \left(C_{1}+L-R, 0\right)+\left(1-\frac{\alpha^{*}}{2}\right) \theta \max \left(C_{1}+C_{2}^{b}-R^{\prime}, 0\right)+(1-\theta) \max \left(C_{1}+C_{2}^{g}-R^{\prime}, 0\right) \geq 0, \\
\frac{\left(1-\frac{\alpha^{*}}{2}\right) \theta}{1-\frac{\alpha^{*} \theta}{2}} \min \left(R^{\prime}, C_{1}+C_{2}^{b}\right)+\frac{(1-\theta)}{1-\frac{\alpha^{*} \theta}{2}} \min \left(R^{\prime}, C_{1}+C_{2}^{g}\right)=R, \\
C_{1}+C_{2}^{o} \geq R>C_{1}+C_{2}^{b} .
\end{gathered}
$$

Here, (A11) is the firm's individual rationality constraint. (A12) ensures that the price of the rolled over debt $R$ is exactly offset by the expected payoff from the rolled over debt represented by the left-hand side of (A12). This also implies that the initial lender can determine $R^{\prime}$ indirectly by adjusting $R$. Note that the probability of the firm rolling over the debt is $1-\frac{\alpha^{*} \theta}{2}$. (A13) is needed because the restriction of $C_{1}+C_{2}^{o} \geq R>C_{1}+C_{2}^{b}$ is imposed.

Finally, suppose that $C_{1}+C_{2}^{o}<R$. Lemma 1(iii) implies that the firm fails to roll over its debt and the initial lender renegotiates with the firm in an out-of-court restructuring or forces the firm into liquidation. It follows from Lemma 2(i)(b) that the debt market participants infer $\omega=o$ because the speculator does not trade. Then, suppose that the initial lender renegotiates with the firm in an out-of-court restructuring. Then, the initial lender can increase her bargaining position by setting the trade order of the CDS to be $x^{\ell}$ $=\lambda\left(C_{1}+C_{2}^{o}\right)-L-C_{1}(>0)$, thereby increasing the firm's pledgeable cash flows by $\lambda\left(C_{1}\right.$ $+C^{o}$ ). Thus, the ex ante expected payoff to the initial lender at date 0 is given by:

$$
\lambda\left(C_{1}+C_{2}^{o}\right)-F .
$$


In fact, if $x^{\ell}>\lambda\left(C_{1}+C_{2}^{o}\right)-L-C_{1}$, the initial lender prefers to collect the insurance payment of CDS at date 1 because the maximum the firm can offer the initial lender in renegotiation at date 1 is $\lambda\left(C_{1}+C^{o}\right)$. Hence, renegotiation cannot occur because setting $x^{\ell}>\lambda\left(C_{1}+C_{2}^{o}\right)-L-C_{1}$ leads to liquidation. Thus, I can focus on the case of $x^{\ell}=$ $\lambda\left(C_{1}+C_{2}^{o}\right)-L-C_{1}$. Consequently, if the initial lender renegotiates with the firm in an out-of-court restructuring, her maximization problem at date 0 is described by:

$$
\max _{R} \lambda\left(C_{1}+C_{2}^{o}\right)-F
$$

subject to:

$$
R>C_{1}+C_{2}^{o}
$$

where (A15) is needed because the restriction of $R>C_{1}+C_{2}^{o}$ is imposed. Note that the firm's ex ante expected payoff at date 0 is zero.

If $C_{1}+C_{2}^{o}<R$ and the initial lender forces the firm into liquidation, the ex ante expected payoff to the initial lender at date 0 is represented by: ${ }^{26}$

$$
\min \left(C_{1}+L, R\right)=C_{1}+L
$$

and the firm's ex ante expected payoff at date 0 is zero in this case. Thus, if the initial lender forces the firm into liquidation, her maximization problem at date 0 is:

$$
\max _{R} C_{1}+L-F
$$

subject to:

$$
R>C_{1}+C_{2}^{o}
$$

where (A17) is again required because the restriction of $R>C_{1}+C_{2}^{o}$ is imposed.

Before solving problems (A7), (A10), (A14), and (A16), I begin by showing that $\Psi>C_{2}^{b}$.

\footnotetext{
${ }^{26}$ See footnote 24 .
} 
Indeed, given $C_{2}^{o} \equiv \theta C_{2}^{b}+(1-\theta) C_{2}^{g}$, it follows from Assumption 1 that:

$$
\Psi-C_{2}^{b}=\frac{\frac{\alpha^{*} \theta}{2}\left(C_{2}^{o}-C_{2}^{b}\right)-(1-\lambda)\left(C_{1}+C_{2}^{o}\right)}{\frac{\alpha^{*} \theta}{2}}>0 .
$$

Thus, there exists a threshold.

Now, I proceed to solve the maximization problem of the initial lender with respect to $R$, $R^{\prime}$, and $x^{\ell}$ by dividing my analysis into three cases: (i) $R \leq C_{1}+C_{2}^{b}$, (ii) $C_{1}+C_{2}^{b}<R \leq$ $C_{1}+C_{2}^{o}$, and (iii) $C_{1}+C_{2}^{o}<R$. Then, comparing the solution in each case, I derive the optimal debt contract and credit protection chosen by the initial lender.

Suppose that $R \leq C_{1}+C_{2}^{b}$. As discussed above, the initial lender's maximization problem at date 0 is represented by maximizing (A7) subject to (A6), (A8), and (A9) with respect to $R \geq 0$ and $R^{\prime} \geq 0$. By setting $R^{\prime}=C_{1}+C_{2}^{b}$, the left-hand side of (A6) is maximized at $R=C_{1}+C_{2}^{b}$ while (A8) and (A9) hold. Then, the initial lender can increase $R$ by $C_{1}+C_{2}^{b}$ so as to maximize (A7) subject to (A6), (A8), and (A9); and her ex ante expected payoff at date 0 is $C_{1}+C_{2}^{b}-F$. As the firm's ex ante expected payoff at date 0 is zero, the firm's value at the beginning of date 0 is also equal to $C_{1}+C_{2}^{b}-F$.

Next, suppose that $C_{1}+C_{2}^{b}<R \leq C_{1}+C_{2}^{o}$. As shown above, the initial lender's maximization problem at date 0 is formalized by maximizing (A10) subject to (A11)-(A13) with respect to $R \geq 0$ and $R^{\prime} \geq 0$. If $R^{\prime}=C_{1}+\frac{1-\frac{\alpha^{*}}{2} \theta}{1-\theta} C_{2}^{\circ}-\frac{\left(1-\frac{\alpha^{*}}{2}\right) \theta}{1-\theta} C_{2}^{b}$, the left-hand side of (A12) is maximized at $R=C_{1}+C_{2}^{o}$ while (A11) and (A13) hold. Then, the initial lender can increase $R$ by $C_{1}+C_{2}^{o}$ so as to maximize (A10) subject to (A11)-(A13); and her ex ante expected payoff at date 0 is $C_{1}+\frac{\alpha^{*} \theta}{2} L+\left(1-\frac{\alpha^{*} \theta}{2}\right) C_{2}^{o}-F$. Because the ex ante expected payoff to the firm, $\frac{\alpha^{*}(1-\theta)}{2}\left(C_{2}^{g}-C_{2}^{\circ}\right)$, is added, the firm's value at the beginning of date 0 becomes $C_{1}+\frac{\alpha^{*} \theta}{2} L+\left(1-\frac{\alpha^{*}}{2}\right) C_{2}^{o}+\frac{\alpha^{*}(1-\theta)}{2} C_{2}^{g}-F$.

Finally, suppose that $C_{1}+C_{2}^{o}<R$ and the initial lender renegotiates with the firm in an out-of-court restructuring. As indicated above, the initial lender's maximization problem at date 0 is described by setting $x^{\ell}=\lambda\left(C_{1}+C_{2}^{o}\right)-L-C_{1}$ and maximizing (A14) subject to (A15) with respect to $R \geq 0$. Under the assumption of $R>C_{1}+C_{2}^{o}$, constraint (A15) is always satisfied. Thus, the initial lender can set $R>C_{1}+C_{2}^{o}$; and her ex ante expected 
payoff at date 0 is $\lambda\left(C_{1}+C_{2}^{o}\right)-F$. As the firm's ex ante expected payoff at date 0 is zero, the firm's value at the beginning of date 0 is also equal to $\lambda\left(C_{1}+C_{2}^{o}\right)-F$. Next, suppose that $C_{1}+C_{2}^{o}<R$ while the initial lender forces the firm into liquidation. Then, her maximization problem at date 0 is to maximize (A16) subject to (A17) with respect to $R \geq 0$, as shown above. Under the assumption of $R>C_{1}+C_{2}^{o}$, constraint (A17) always holds. Then, the initial lender's ex ante expected payoff at date 0 is $C_{1}+L-F$. Given the assumption of $C_{1}+L<\lambda\left(C_{1}+C_{2}^{o}\right)$, the initial lender prefers renegotiating with the firm in an out-of-court restructuring rather than forcing the firm into liquidation.

I am now in a position to compare the solutions in the above three cases and to derive the optimal debt contract and credit protection chosen by the initial lender. First, it follows from the assumptions of $C_{2}^{b}<L<C_{2}^{o}<C_{2}^{g}$ and $C_{1}+L<\lambda\left(C_{1}+C_{2}^{o}\right)$ that the maximal ex ante expected payoff of the initial lender at date 0 in the case of $R \leq C_{1}+C_{2}^{b}$ is lower than that in any other case. Thus, I can drop the case of $R \leq C_{1}+C_{2}^{b}$. Hence, the remaining problem is to compare the maximal ex ante expected payoffs of the initial lender at date 0 in the cases of $C_{1}+C_{2}^{b}<R \leq C_{1}+C_{2}^{o}$ and $C_{1}+C_{2}^{o}<R$. Given that the initial lender prefers to renegotiate with the firm in an out-of-court restructuring when $C_{1}+C_{2}^{o}<R$, the maximal ex ante expected payoffs of the initial lender at date 0 in the cases of $C_{1}+C_{2}^{b}<$ $R \leq C_{1}+C_{2}^{o}$ and $C_{1}+C_{2}^{o}<R$ are $C_{1}+\frac{\alpha^{*} \theta}{2} L+\left(1-\frac{\alpha^{*} \theta}{2}\right) C_{2}^{o}-F$ and $\lambda\left(C_{1}+C_{2}^{o}\right)-F$, respectively. Then, it follows that $\lambda\left(C_{1}+C_{2}^{o}\right)-F \geq(<) C_{1}+\frac{\alpha^{*} \theta}{2} L+\left(1-\frac{\alpha^{*} \theta}{2}\right) C_{2}^{o}-F$ if $\Psi \geq(<) L$, where $\Psi \equiv \frac{\left(\frac{\alpha^{*} \theta}{2}+\lambda-1\right) C_{2}^{o}-(1-\lambda) C_{1}}{\frac{\alpha^{*} \theta}{2}}$. The other statements of this proposition are evident from Lemmas 1(ii) and 2(i).

Proof of Proposition 3: Note that $C_{1}+\frac{\alpha^{*} \theta}{2} L+\left(1-\frac{\alpha^{*}}{2}\right) C_{2}^{o}+\frac{\alpha^{*}(1-\theta)}{2} C_{2}^{g}-F>C_{1}+$ $C_{2}^{o}-F>\lambda\left(C_{1}+C_{2}^{o}\right)-F$ because of $L>C_{2}^{b}$ and $C_{2}^{o} \equiv \theta C_{2}^{b}+(1-\theta) C_{2}^{g}$. Then, if $\Psi \geq$ $L$, it follows from Propositions 1 and 2(i) that statement (i) is verified. If $L>\Psi$, it follows from Propositions 1 and 2(ii) that the speculator's information acquisition costs need to be considered in the case of CDS introduction. More specifically, I need to check whether $C_{1}$ $+\frac{\alpha^{*} \theta}{2} L+\left(1-\frac{\alpha^{*}}{2}\right) C_{2}^{o}+\frac{\alpha^{*}(1-\theta)}{2} C_{2}^{g}-F-c\left(\alpha^{*}\right) \geq C_{1}+C_{2}^{o}-F$. Given $C_{2}^{o} \equiv \theta C_{2}^{b}+(1-$ $\theta) C_{2}^{g}$, the first part of statement (ii) is verified. Finally, if $c(\alpha)=\frac{1}{2} \eta(\alpha)^{2}$, it follows from $\alpha^{*}$ 
$=c^{\prime-1}(\theta(1-\theta) n)$ that the condition in the first part of statement (ii) can be rewritten as $(1-\theta) n>(\leq) L-C_{2}^{b}$. As a result, the latter part of statement (ii) is evident.

Proof of Proposition 4: I begin by examining the effects of $\alpha, \lambda, L, C_{1}$, and $\theta$ on $\Psi$. Taking $\alpha$ as given exogenously and using $\Psi \equiv \frac{\left(\frac{\alpha \theta}{2}+\lambda-1\right) C_{2}^{o}-(1-\lambda) C_{1}}{\frac{\alpha \theta}{2}}$ I have:

$$
\frac{\partial \Psi}{\partial \alpha}=\frac{1}{\frac{\alpha^{2} \theta}{2}}(1-\lambda)\left(C_{1}+C_{2}^{o}\right)>0, \frac{\partial \Psi}{\partial \lambda}=\frac{1}{\frac{\alpha \theta}{2}}\left(C_{1}+C_{2}^{o}\right)>0, \frac{\partial \Psi}{\partial L}=0, \frac{\partial \Psi}{\partial C_{1}}=-\frac{(1-\lambda)}{\frac{\alpha \theta}{2}}<0 .
$$

In addition, using $C_{2}^{o} \equiv \theta C_{2}^{b}+(1-\theta) C_{2}^{g}$, I obtain:

$$
\frac{\partial \Psi}{\partial \theta}=\frac{1}{\frac{\alpha \theta^{2}}{2}}\left[\left(1-\lambda-\frac{\alpha \theta^{2}}{2}\right) C_{2}^{g}+\frac{\alpha \theta^{2}}{2} C_{2}^{b}+(1-\lambda) C_{1}\right]
$$

In view of Proposition 2, the comparative static results regarding $\alpha, \lambda$, and $C_{1}$ in Proposition 4 are verified because an increase in $\alpha$ or $\lambda$ or a decrease in $C_{1}$ enlarges the range of $\Psi \geq L$. If $1-\lambda>\frac{\alpha \theta^{2}}{2}$, the result regarding $\theta$ in Proposition 4 is also proved, because an increase in $\theta$ expands the range of $\Psi \geq L$. It is also evident from Proposition 2 that the result regarding $L$ holds because a smaller $L$ is more likely to stay in the range of $\Psi \geq L$.

Proof of Lemma 6: I can focus on the case of $C_{1}+C_{2}^{b}<R \leq C_{1}+C_{2}^{o}$ because of the reasons explained above (A4) in the proof of Lemma 5. Then, $\alpha^{*}$ is determined by (A5). Now, totally differentiating (A5) with respect to $\alpha^{*}, \theta$, and $n$ yields:

$$
\begin{gathered}
\frac{d \alpha^{*}}{d \theta}=\frac{(1-2 \theta) n}{c^{\prime \prime}\left(\alpha^{*}\right)} \gtreqless 0, \text { if and only if } \frac{1}{2} \gtreqless \theta . \\
\frac{d \alpha^{*}}{d n}=\frac{\theta(1-\theta)}{c^{\prime \prime}\left(\alpha^{*}\right)}>0 .
\end{gathered}
$$

In addition, $\alpha^{*}$ is independent of $\lambda, L$, and $C_{1}$ regardless of the size of $R$. Hence, Lemma 6 is verified.

Proof of Proposition 5: I first prove the result regarding $n$. To this end, it follows from (A18) and (A21) that $\frac{d \Psi}{d n}=\frac{\partial \Psi}{\partial \alpha^{*}} \frac{d \alpha^{*}}{d n}>0$. Thus, given Proposition 2, out-of-court restructuring 
is more likely to arise in equilibrium if $n$ is larger.

Next, for the result about $\theta$, it follows from (A18)-(A20) that $\frac{d \Psi}{d \theta}=\frac{\partial \Psi}{\partial \theta}+\frac{\partial \Psi}{\partial \alpha^{*}} \frac{d \alpha^{*}}{d \theta}>0$ if 1 $-\lambda>\frac{\alpha^{*} \theta^{2}}{2}$ and $\frac{1}{2} \geq \theta$, where $\alpha^{*}=c^{-1}(\theta(1-\theta) n)$. Thus, Proposition 2 again indicates that if $1-\lambda>\frac{\alpha^{*} \theta^{2}}{2}$ and $\frac{1}{2} \geq \theta$, out-of-court restructuring is more likely to arise in equilibrium if $\theta$ is larger.

The results regarding $\lambda, L$, and $C_{1}$ are evident from Proposition 4 and Lemma 6 . 


\section{References}

Acharya, V. V., and T. C. Johnson, 2007, Insider Trading in Credit Derivatives, Journal of Financial Economics 84, 110-141.

Ashcraft, A. B., and J. A. C. Santos, 2009, Has the CDS Market Lowered the Cost of Corporate Debt? Journal of Monetary Economics 56, 514-523.

Asriyan, V., W. Fuchs, and B. Green, 2017, Information Spillovers in Asset Markets with Correlated Values, American Economic Review 107, 2007-2040.

Bao, J., J. Pan, and J. Wang, 2011, The Illiquidity of Corporate Bonds, Journal of Finance 66, 911-946.

Bedendo, M., L. Cathcart, and L. El-Jahel, 2016, Distressed Debt Restructuring in the Presence of Credit Default Swaps, Journal of Money, Credit and Banking 48, 165-201.

Bessembinder, H., W. Maxwell, and K. Venkataraman, 2006, Market Transparency, Liquidity Externalities, and Institutional Trading Costs in Corporate Bonds, Journal of Financial Economics 82, 251-288.

Bigus, J., and H. Hakenes, 2014, Does Relationship Lending Require Opaque (and Conservative) Financial Reporting, CEPR Discussion No. 9934.

Blanco, R., S. Brennan, and I. W. Marsh, 2005, The Determinants of Long-term Corporate Debt Issuances, Journal of Finance 60, 2255-2281.

Bolton, P., and M. Oehmke, 2011, Credit Default Swaps and the Empty Creditor Problem, Review of Financial Studies 24, 2617-2655.

Bolton, P., and M. Oehmke, 2012, Should Derivatives be Privileged in Bankruptcy?, Journal of Finance 65, 1994-1986.

Dang, T. V., G. Gorton, B. Holmström, and G. Ordoñez, 2017, Banks as Secret Keepers, American Economic Review 107, 1005-1029.

Danis, A., 2017, Do empty Creditors Matter? Evidence from Distressed Exchange Offers, Management Science 63, 1285-1301.

Danis, A., and A. Gamba, 2018, The Real Effects of Credit Default Swaps, Journal of Financial Economics 127, 51-76.

Das, S., M. Kalimipalli, and S. Nayak, 2014, Did CDS Trading Improve the Market for 
Corporate Bonds? Journal of Financial Economics 111, 495-525.

Davydenko, S. A., and I. A. Strebulaev, 2007, Strategic Actions and Credit Spreads: An Empirical Investigation, Journal of Finance 62, 2633-2671.

Duffee, G. R., and C. Zhou, 2001, Loan Sales and Relationship Banking, Journal of Monetary Economics 48, 25-54.

Edwards, A., L. E. Harris, and M. S. Piwowar. 2007, Corporate Bond Market Transaction Costs and Transparency, Journal of Finance 62, 1189-1222.

Forte, S., and J. I. Peña, 2009, Credit Spreads: An Empirical Analysis on the Informational Content of Stocks, Bonds, and CDS, Journal of Banking and Finance 33, 2013-2025.

Hilscher, J., J. M. Pollet, and M. Wilson, 2015, Are Credit Default Swaps a Sideshow? Evidence That Information Flows from Equity to CDS Markets, Journal of Financial and Quantitative Analysis 50, 543-567.

Hotchkiss, E.S., and T. Ronen, 2002, The Informational Efficiency of the Corporate Bond Market: An Intraday Analysis, Review of Financial Studies 15, 1324-1354.

Hull, J., M. Predescu, and A. White, 2004, The Relationship between Credit Default Swap Spreads, Bond Yields, and Credit Rating Announcements, Journal of Banking and Finance 28, 2789-2811.

Jorion, P., and G. Zhang, 2007, Good and Bad Credit Contagion: Evidence from Credit Default Swaps, Journal of Financial Economics 84, 860-883.

Kedia, S., and X. Zhou, 2014, Informed Trading around Acquisitions: Evidence from Corporate Bonds, Journal of Financial Markets 18, 182-205.

Kyle, A., 1985, Continuous Auctions and Insider Trading, Econometrica 53, 1315-1335.

Lee, J., J. Oh, and D. Yermack, 2017, Credit Default Swaps, Agency Problems, and Management Incentives, NBER Working Paper No.24064.

Lee, J., A. Naranjo, and G. Velioglu, 2018, When Do CDS Spreads Lead? Rating Events, Private Entities, and Firm-Specific Information Flows, Journal of Financial Economics 130, $556-578$.

Monnet, C., and E. Quintin, 2017, Rational Opacity, Review of Financial Studies 30, 43174348. 
Norden, L. and W. Wagner, 2008, Credit derivatives and Loan Pricing, Journal of Banking and Finance 32, 2560-2569.

Oehmke, M. and A. Zawadowski, 2015, Synthetic or Real? The Equilibrium Effects of Credit Default Swaps on Bond Markets, Review of Financial Studies 28, 3303-3337.

Pagano, M., and P. Volpin, 2012, Securitization, Transparency, and Liquidity, Review of Financial Studies 25, 2417-2453.

Parlour, C. A., and G. Plantin, 2008, Loan Sales and Relationship Banking, Journal of Finance 63, 1291-1314.

Piccolo, A., and J. Shapiro, 2017, Credit Ratings and Market Information, CEPR Discussion Paper No. 11961.

Ronen, T., and X. Zhou, 2013, Trade and Information in the Corporate Bond Market, Journal of Financial Markets 16, 61-103.

Saretto, A. and H. E. Tookes, 2013, Corporate Leverage, Debt Maturity, and Credit Supply: The Role of Credit Default Swaps, Review of Financial Studies 26, 1190-1247.

Subrahmanyam, M. G., D. Y. Tang, and S. Q. Wang, 2014, Does the Tail Wag the Dog?: The Effect of Credit Default Swaps on Credit Risk, Review of Financial Studies 27, 2926-2960.

Qiu, J., and F. Yu, 2012, Endogenous Liquidity in Credit Derivatives, Journal of Financial Economics 103, 611-631.

Stultz, R. M., 2010, Credit Default Swaps and the Credit Crisis, Journal of Economic Perspectives $24,73-92$.

Vanasco, V., 2017, The Downside of Asset Screening for Market Liquidity, Journal of Finance $72,1937-1981$. 


\begin{tabular}{|c|c|c|c|c|}
\hline$t=0$ & & & $\mathrm{t}=1$ & $\mathrm{t}=2$ \\
\hline Initial Debt & Information & Belief & $\mathrm{C}_{1}$ is realized & $\mathrm{C}_{2}$ is realized \\
\hline \multirow[t]{4}{*}{ Contract } & Acquisition & Revision & & \\
\hline & and Trade in & & & \\
\hline & the CDS & & & \\
\hline & Market & & & \\
\hline \multirow{14}{*}{$\begin{array}{l}\text { The initial lender } \\
\text { signs an initial } \\
\text { debt contract with } \\
\text { the firm. }\end{array}$} & The speculator & The debt market & If the firm can roll over & The holders of the rolled \\
\hline & decides whether & participants revise & the initial debt, the firm & over debt and the firm \\
\hline & to acquire & their beliefs about & continues the project. If & obtain their claims \\
\hline & information & the firm's date 2 & the firm fails to roll over & according to the rolled \\
\hline & about the firm's & cash flows. & the initial debt, the initial & over debt contract. \\
\hline & date 2 cash flows & & lender either forces the & If the credit event occurs, \\
\hline & or not. The & & firm into liquidation or & the protection buyer \\
\hline & speculator, & & renegotiates with the & receives the $\mathrm{CD}$ \\
\hline & noise traders, and & & firm in an out-of-court & payment from the \\
\hline & the initial lender & & restructuring. If the credit & protection seller. \\
\hline & submit their trade & & event occurs, the protection & \\
\hline & orders to the market & & buyer receives the CDS & \\
\hline & maker if they want & & payment from the protection & \\
\hline & to trade CDS. & & seller. & \\
\hline
\end{tabular}

Figure 1. Model Timeline 